\title{
Kapitel III \\ Genderidentität im Gefängnis: Sexuelle Versuchung und Widerstand
}

Das vorliegende Kapitel befasst sich mit der Konstruktion der Genderidentität der Märtyrerinnen, welche weitgehend bei ihrer Inhaftierung sichtbar wird. Das Gefängnis ist im Fall der Märtyrerinnen ein idealer Ort, an dem ungläubige Männer bzw. Dämonen und Drachen in greifbarer Gestalt erscheinen können, um der jeweiligen Protagonistin sexuelle Gewalt anzutun bzw. sie in sexuelle Versuchung zu führen. Bei der Begegnung der inhaftierten Märtyrerin mit dem dämonischen bzw. männlichen Widersacher handelt es sich meiner Ansicht nach um einen Kampf der Protagonistin zur Bewahrung ihrer Keuschheit. Mit anderen Worten streben diese Widersacher danach, die Protagonistin zu vergewaltigen, sie ihrer Jungfräulichkeit zu berauben und damit ihre Glaubensfestigkeit zu erschüttern. Daher haben am häufigsten auch die körperlichen Folterungen, denen die christliche Protagonistin unterzogen wird, einen sexuellen Charakter. ${ }^{1}$

Die Gegner wählen den Gefängnisraum zu diesem Zweck aus, weil sich dort die jeweilige Märtyrerin alleine und isoliert bzw. weit entfernt von den Augen der Zuschauer und jeder möglichen Hilfe befindet. Außerdem ist die Märtyrerin in einer begrenzten Zelle eingeschlossen, aus der sie nicht entkommen kann. Das Bild einer inhaftierten Jungfrau, deren Keuschheit durch den Angriff eines bösen Wesens in Gefahr schwebt, erinnert an einen auch unter den Byzantinern bekannten griechischen Mythos, gemäß dem der Göttervater Zeus das junge Mädchen Danaë während ihrer Inhaftierung sexuell verführte und schwängerte. ${ }^{2}$ In den Märtyrerakten aber, welche von christlichen Autoren abgefasst wurden, wird Zeus entweder durch dämonische Kreaturen oder durch deren Vertreter auf Erden, nämlich zudringliche pagane Männer, ersetzt, wobei es der inhaftierten Märtyrerin mit Gottes Hilfe immer gelingt, die sexuelle Gefahr abzuwehren. In diesem Sinne wird die Spiritualität der Protagonistin in der Ablehnung sämtlicher sexueller Aktivitäten betont.

\footnotetext{
1 Zur sexuellen Dimension der Frauenmärtyrerakten und zum Zusammenhang zwischen Jungfräulichkeit und Glaubensfestigkeit im Fall der Märtyrerinnen s. WILSON, Female Sanctity in the Greek Calendar, 243-245; KAY, The Sublime Body of the Martyr, bes. 14-17; KAY, Courtly Contradictions, 226229; Constantinou, Female Corporeal Performances, 22, 34-38, 53-55; Constantinou, Virginity in

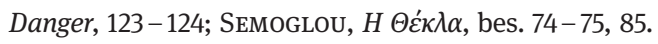

2 Angesichts der Tatsache, dass Danaë von ihrem Vater inhaftiert wurde, kann diese Geschichte auch mit den Märtyrerakten von Barbara (PBar BHG 213-214; Met-PBar BHG 216), Christina (BHG 301y302b) und Irene (BHG 952y-954c) verbunden werden, deren Väter sie zur Erhaltung ihrer Jungfräulichkeit in einen Turm sperrten. Für die Beispiele von Barbara und Christina im Zusammenhang mit Danaë und die byzantinische Rezeption dieses griechischen Mythos s. PAPAIOANnou, Christian Novels,

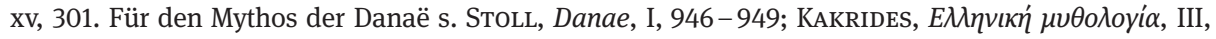
181-182 (mit einschlägigen Abbildungen).
} 
Die Bewahrung der Jungfräulichkeit symbolisiert den siegreichen Widerstand der Märtyrerin gegen die paganen Gegner, ihren starken Willen zur Verteidigung ihres Glaubens und ihre Standhaftigkeit bis in den Tod. Jungfräulichkeit ist ein zentraler Baustein bei der Konstruktion der Heiligkeit einer Märtyrerin, weswegen die große Mehrheit der Märtyrerinnen Jungfrauen sind und die Hagiographen diese Eigenschaft ihrer Protagonistinnen immer wieder unterstreichen. ${ }^{3}$ Die Keuschheit einer Frau gilt ohnehin nach der frühchristlichen Ideologie als das Ideal für ihre Vollkommenheit. ${ }^{4}$ In seinem Werk De virginitate (CPG 4313) versteht beispielsweise Johannes Chrysostomos unter dem Begriff Jungfräulichkeit nicht nur die körperliche Enthaltsamkeit von allen sexuellen Genüssen, sondern auch die Reinheit der Seele, sodass eine Frau Christus im übertragenen Sinne ehelichen bzw. zu ihm ins Paradies gelangen kann: „Eine Jungfrau muss nicht nur körperlich rein sein, sondern auch seelisch, wenn sie den heiligen Bräutigam empfangen möchte. [...] Definition der Jungfräulichkeit ist also

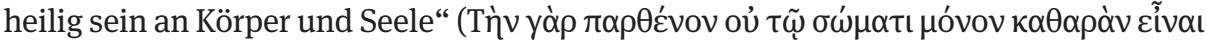

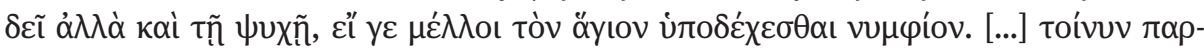

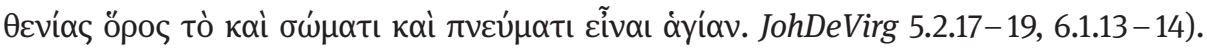
Aufgrund einer gründlichen Untersuchung von asketischen Texten der Spätantike kommt Antoine Guillaumont zu dem Schluss, dass die Jungfräulichkeit Unzerstörbarkeit (incorruptibilité) und Unsterblichkeit (immortalité) gewährleistet. ${ }^{5}$ Unzerstörbarkeit und Unsterblichkeit stellen Charakteristika der Ewigkeit bzw. der Heiligkeit dar. Der Märtyrerin wird also durch die Bewahrung ihrer seelischen und körperlichen Keuschheit sowie die Erduldung des gewaltsamen Todes der Heiligkeitsstatus verliehen.

Es sollte nicht vergessen werden, dass die Hagiographie neben ihrer didaktischen Funktion der Vermittlung von Frömmigkeitsbeispielen auch als Trivialliteratur diente, da sie einem breiten Publikum Unterhaltung bot. ${ }^{6}$ Dazu trug wohl auch die Schilderung der sexuell ausgerichteten Folter bzw. sexualisierten Gewalt gegen die Märtyrerinnen bei, welche vorwiegend dem männlichen Teil des Publikums sexuelles Vergnügen gewährte. ${ }^{7}$ Hierbei ist zu erwähnen, dass die überwältigende Mehrheit der Märtyrerakten bzw. der hagiographischen Texte allgemein von Männern abgefasst

3 Constantinou, Female Corporeal Performances, 54.

4 Guillaumont, Le célibat monastique, 83-98 [161-178]; TAlBot, Women, 118.

5 Guillaumont, Le célibat monastique, bes. 97-98 [176-177].

6 Herbert Hunger macht insbesondere im Hinblick auf die byzantinischen Chronisten folgende Bemerkung: „Triviale Motivwahl, Sprache und Handlungsführung, schablonenhafte Zeichnung von Figuren und Umwelt und leichte Lesbarkeit zeichnen dieses Genos aus. Werke der Trivialliteratur wollen in erster Linie Unterhaltung für ein ,breites' Publikum bieten“: HunGER, Die hochsprachliche profane Literatur, 257. Zur Hagiographie als Trivialliteratur s. KAzHDAN, Byzantine Hagiography and Sex, bes. 131 .

7 Zur byzantinischen Hagiographie als Unterhaltungsmittel des männlichen Publikums s. KAZHDAN, Byzantine Hagiography and Sex, 131-143; Constantinou, Female Corporeal Performances, 22-23, mit Anm. 2, 34-38. 
wurde und daher den männlichen Blick auf die heiligen Frauen widerspiegelt. ${ }^{8}$ Im metaphrastischen Menologion konnte es den Märtyrerakten sogar einen besonderen

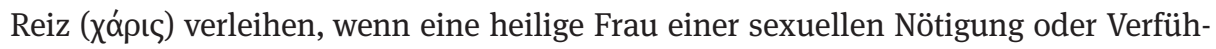
rung entging, was die Rezipienten habe verblüffen oder auch amüsieren können. ${ }^{9}$ In diesem Zusammenhang bemerkt Stavroula Constantinou: Hagiographie „offered sexual entertainment appearing less ,harmful' under the guise of piety“ ${ }^{10}{ }^{10}$ Genau deswegen werden in der neueren Forschung so gestaltete Texte der hagiographischen Literatur als die „männliche Pornographie“ des Mittelalters bezeichnet. ${ }^{11}$

Auf der einen Seite können Interesse und Lust byzantinischer Verfasser, Leser und Zuhörer an der Darstellung von malträtierten Körpern und in Vergewaltigungsgefahr schwebenden Märtyrerinnen festgestellt werden, was eine Tendenz zu Aggressivität, Brutalität und Sadismus vermuten lässt. ${ }^{12}$ Wenn man aber auf der anderen Seite bedenkt, dass die hagiographischen Texte hauptsächlich beim Gottesdienst in einer Gemeindekirche oder einem Kloster öffentlich vorgelesen und rezipiert wurden, ${ }^{13}$ kann das erotische bzw. sexuelle Element in diesen Texten auch als eine öffentliche gemeinschaftliche Übung der Gläubigen zur Bewältigung derartiger Versuchungen gesehen werden. Dieselbe Funktion sollten auch die ikonographischen Darstellungen von nackten Körpern in Fresken byzantinischer Kirchen erfüllen, wie etwa die von sündigen (Männern und) Frauen im Kontext des Jüngsten Gerichts. ${ }^{14}$ Die Byzantiner vermieden es hingegen, die Nacktheit heiliger Frauen, insbesondere Märtyrerinnen, in Fresken darzustellen. ${ }^{15}$ So fungierten wohl die in den hagiographischen Texten be-

8 Vgl. Constantinou, Subgenre and Gender, 415-416, mit Anm. 5; Hinterberger, The Byzantine Hagiographer and His Text, 215.

9 HinteRBERGER, Byzantinische biographische Literatur, 77-78.

10 Constantinou, Female Corporeal Performances, 22-23.

11 Zur Hagiographie und Pornographie s. BuRgwinkle - Howie, Sanctity and Pornography; ConSTANTINou, Bloodthirsty Emperors.

12 Diese Anmerkung macht Herbert Hunger in Bezug auf die makabren Details, die die Gattung der byzantinischen Chronistik bei der Schilderung verschiedener Ereignisse beinhaltet, vgl. HunGER, Die hochsprachliche profane Literatur, 257, 273-274. Es scheint, dass diese Anmerkung auch auf die Gattung der Hagiographie zutrifft.

13 Für die öffentliche Verlesung der hagiographischen Schriften in Kirchen und Klöstern s. zuletzt EFTHYMiadis, Introduction, bes. 13; EFTHYMiadis - Kalogeras, Audience, Language and Patronage, bes. 248 (mit weiteren Nachweisen). In geringerem Maße dienten aber diese Texte auch der Privatlektüre. Mit dem Verwendungskontext und -zweck der hagiographischen Literatur befasste ich mich im Rahmen meiner Masterarbeit, in der weitere bibliographische Angaben zu finden sind, vgl. PAPAvarnavas, Die Rolle des Publikums, 42-69, 78-95 (mit tabellarischer Darstellung der Hauptergebnisse).

14 Ein ikonographisches Beispiel von nackten Sündern und Sünderinnen, datiert ins Jahr 1332/1333, ist in der byzantinischen Kirche der Panagia von Asinou bzw. Panagia Phorviotissa auf Zypern anzutreffen. Diesbezüglich s. HeIn - JAKovljević - KLEIDT, Zypern, bes. 59-60, mit Abb. 32-35; Kalopissi-VerTi, The Murals of the Narthex, bes. 144-148, mit Abb. 5.27.

15 Aus offizieller byzantinischer Sicht wurde allgemein die Darstellung der Nacktheit in der Kunst verurteilt, sofern sie nicht einem eindeutig christlichen Zweck diente, nämlich der Demonstration der menschlichen Natur Christi bei seiner Taufe und Kreuzigung, der Zurschaustellung der schändlichen 
schriebenen Märtyrerinnen mit ihrem malträtierten bzw. nackten Körper infolge ihres Widerstands gegen die sexuellen Verlockungen als Beispiele zur Nachahmung für die Zielgruppe, während die sündigen (Männer und) Frauen mit ihrem nackten und gequälten Körper, visualisiert im Bildprogramm einer Kirche, als Beispiele zur Vermeidung dienten. Das träfe dann natürlich auch auf die seltenen Fälle zu, in denen die hagiographischen Schriften zur Entfaltung der eigenen Frömmigkeit privat gelesen wurden. Jedenfalls kann die hagiographische Literatur wegen ihres Erbauungs- und Unterhaltungscharakters als das „Fernsehen der Epoche“ betrachtet werden. All diese Vorkenntnisse sollte man im Hinterkopf haben, um die Interpretation der erotischen bzw. sexuellen Konnotation der folgenden Gefängnisszenen nachzuvollziehen.

\section{III.1 Die inhaftierte Märtyrerin gegen Dämonen und Drachen}

Die Gegenwart des Dämons wird in den Märtyrerakten und Heiligenviten vorwiegend auf drei Weisen angegeben: entweder abstrakt als die Quelle allen Übels, wie etwa der sexuellen Verlockungen, welche weibliche und männliche Märtyrer und Asketen bewältigen müssen, oder durch die von Dämonen besessenen Menschen, die mithilfe der Protagonisten geläutert werden, oder als eine direkte Bedrohung, wenn die Dämonen eine konkrete Gestalt annehmen und sich mit den heiligen Personen einen

Nacktheit Adams und Evas oder der Abbildung der Selbstverleugnung bestimmter asketischer - zumal männlicher - Heiliger, unter denen sich ausnahmsweise auch Maria von Ägypten findet, vgl. DAUTERMAn Maguire - Maguire, Other Icons, bes. 97-109. Außerdem wurde Nacktheit in der byzantinischen religiösen Kunst oft mit dämonisierten bzw. sündigen Personen assoziiert, wobei ihre Abbildung bei den Betrachtern sogar ein Schamgefühl habe auslösen können, dazu s. ZEITLER, Ostentatio genitalium, 192-193, 199-200 (mit weiterer Literatur). Märtyrerinnen wurden folglich in der Regel nicht nackt dargestellt. Meines Wissens bildet die heilige Thekla, die zwar keinen Märtyrertod erlitt, aber vielen Folterungen durch ihre paganen Verfolger unterzogen wurde, eine der wenigen Ausnahmen. Eine neue archäologische Forschung konnte nämlich erstmals die nackte weibliche Figur auf verschiedenen Ritualgegenständen, welche hauptsächlich vom 5. bis zum 7. Jahrhundert bei Taufen, Beerdigungen und Gottesdiensten in Ägypten Verwendung finden sollten, mit der heiligen Thekla

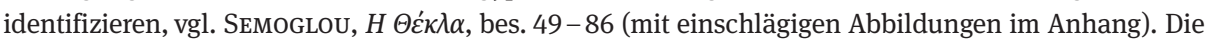
Tatsache, dass Darstellungen von nackten Märtyrerinnen höchst selten anzutreffen sind, war wahrscheinlich der Grund dafür, dass alle vorherigen archäologischen Forschungen zu den besagten Gegenständen diese weibliche Figur entweder überhaupt nicht identifizieren konnten oder auf problematische Weise mit mythischen Gestalten, wie Aphrodite und Daphne, in Verbindung brachten. Darüber hinaus konnte ich im Laufe meiner Forschungen außerdem zwei Abbildungen von halbnackten Märtyrerinnen entdecken. Es handelt sich dabei um zwei in einer berühmten Handschrift (Codex Vat. gr. 1613) befindlichen Miniaturen, welche die Märtyrerin Karina (fol. 165) und die Märtyrerin Agatha (fol. 373) im Moment ihres sexualisierten Leidens (Abschneiden der Brüste) illustrieren. In der genannten Handschrift werden die recto- und verso-Seiten durchgängig foliiert: http://digi.vatlib.it/ view/MSS_Vat.gr.1613 (abgerufen am 19. Juni 2020). 
körperlichen Kampf liefern. ${ }^{16}$ In Bezug auf die dritte Erscheinungsform der Dämonen, auf die hier näher einzugehen ist, fasst Claudia Rapp alle relevanten Informationen wie folgt zusammen: „In allen wichtigen Momenten des Lebenswegs bestand also die Möglichkeit eines Einwirkens negativer Kräfte. [...] Sie [d.h. die Dämonen] erscheinen in der Gestalt von Menschen (besonders als Dunkelhäutige oder Frauen) und Tieren, sind aggressiv und heimtückisch, und lauern auf ihre Opfer bevorzugt an Orten oder in Momenten des Übergangs (Türschwellen, Taufe, Tod)““. ${ }^{17}$

Im Fall der Märtyrer stellt das Gefängnis eine wichtige Übergangsphase zur Erlangung der Heiligkeit dar und seine entscheidende Bedeutung wird durch die Anwesenheit von Dämonen hervorgehoben. Laut Tertullian ist das Gefängnis die Behausung des Teufels und der Dämonen, welche die inhaftierten Märtyrer in die Flucht schlagen sollen:

Wohnung des Teufels ist nämlich auch ein Kerker, worin er seine Angehörigen einschließt. Ihr aber [d.h. die Märtyrer] seid gerade deswegen in den Kerker gekommen, um ihn auch in seinem eigenen Hause niederzutreten. ${ }^{18}$

Domus quidem diaboli est et carcer, in qua familiam suam continet; sed vos ideo in carcerem pervenistis, ut illum etiam in domo sua conculcetis. (TertMart Kap.1.17-19)

Den hier untersuchten Märtyrerakten nach vertreiben die christlichen Protagonisten die Dämonen und befreien damit den Gefängnisraum vom Bösen.

In dieser Einheit soll die Erscheinung des Dämons im Gefängnis weiter diskutiert werden, die aus der Genderperspektive eine interessante Besonderheit aufweist: Obgleich Christus und die Engel sehr häufig sowohl den Märtyrern als auch den Märtyrerinnen im Gefängnis erscheinen, tritt der Dämon sehr selten auf, und wenn, dann erscheint er nur den inhaftierten Märtyrerinnen. Das macht einen wesentlichen Unterschied zwischen den Märtyrerakten und den Heiligenviten aus, in denen Teufel und Dämonen den Asketen und Asketinnen unabhängig von deren Geschlecht erscheinen. ${ }^{19}$ Während die Forschung dem dämonischen Element in den asketischen Heiligenviten große Aufmerksamkeit widmete, ${ }^{20}$ wurde dies im Zusammenhang mit den Märtyrerakten noch nicht systematisch untersucht. In der folgenden Diskussion werden uns also hauptsächlich die Märtyrerakten der Juliana von Nikomedien (PJulNic BHG 962z, 5./6. Jh.; Met-PJulNic BHG 963, 10. Jh.) beschäftigen, welche in mein

16 Vgl. Dölger, Der Kampf mit dem Ägypter, 177-188; Dinzelbacher, Der Kampf der Heiligen, 647695; Boulhol, Hagiographie antique et démonologie, 269-279; DinzelbaCher, Angst im Mittelalter, bes. $27-66$.

17 RAPP, Heilige, Teufel und Dämonen, 108-109.

18 Übers. mit leichten Änderungen nach KELLNER, Tertullians private und katechetische Schriften, 216. 19 Paradebeispiele dafür bieten die Vita des heiligen Antonios (VAnt BHG 140, Kap.5.1-43, 6.1-28, 8.1-25, 9.1-43, 10.1-18, 12.1-23, 13.1-31, 51.1-22, 52.1-14, 53.1-13) und die Vita der Irene von Chrysobalanton (VIrChrys BHG 952, S.44.14-27, S.46.1-26, S.48.1-18).

20 S. bspw. die Werke von HARPhAM, The Ascetic Imperative und BraKke, Demons and the Making of the Monk. 
Haupttextkorpus einbezogen sind. Dazu sind auch die Märtyrerakten der Marina von Antiochien (PMarAnt BHG 1165, spätestens im 7. Jh.) und die vom Lateinischen ins Griechische übertragenen Märtyrerakten von Perpetua und Felicitas (PPerFel BHG 1482, 3./4. Jh.) zu berücksichtigen, in denen das dämonische Element vorherrschend ist. ${ }^{21}$ Obgleich die beiden letzteren Märtyrerakten nicht zu den metaphrastischen Texten und ihren Vorlagen gehören, untersuche ich sie hier, um ein vollständigeres Bild der Dämonenerscheinung im Gefängnis zu vermitteln.

Über die Dämonen hinaus dienen auch die Drachen in den Märtyrerakten als furchtbare Widersacher der heiligen Personen. Obgleich beide Figuren, nämlich Dämonen und Drachen, den Kräften des Bösen angehören, können sie als zwei unterschiedliche übernatürliche Wesen betrachtet werden. ${ }^{22}$ Während in den Märtyrerakten der ersten Christen die Figur eines Drachen meist in greifbarer Gestalt erscheint, ist sie in den auf einer möglichst realistischen Basis fundierten Viten von ikonophilen Märtyrern nur als Metapher für den zornigen ikonoklastischen Kaiser anzutreffen (vgl. VStephIun BHG 1666, S.154.21, S.155.5-6, S.165.1, S.166.28, S.173.10; Met-VStephIun $B H G$ 1667, S.103.904). ${ }^{23}$ Aus meiner intensiven Lektüre von Märtyrerakten des hier behandelten Zeitraums ergibt sich, dass die Erscheinung eines Drachen in greifbarer Gestalt ein ziemlich häufiges Motiv in den Männermärtyrerakten darstellt (ActThom BHG 1808, Kap.30 - 33; PThStr BHG 1751, S.153.1-31, S.154.1-33, S.155.1-31, S.156.1-7; PThTer BHG 1761-1762d, S.127.11-20; Met-PThTer BHG 1763, S.137.4-29, S.138.1-24; PAthen BHG 197b, Kap.4-6; MiracGeorg BHG 687, S.113-129). ${ }^{24}$ In diesen Fällen be-

21 Für die Datierung der Märtyrerakten der Juliana von Nikomedien und jener der Marina von Anti-

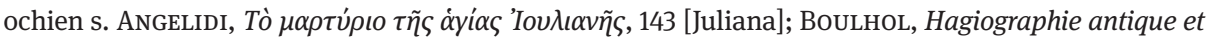
démonologie, 259-261 [Juliana und Marina]. Für die Abfassungszeit der Märtyrerakten von Perpetua und Felicitas s. hier die Einleitung.

22 White, The Rise of the Dragon, bes. 149-150. Vgl. dagegen die Auffassung von Pascal Boulhol, dass diese Figuren auf direkte oder indirekte Weise identifiziert werden: BoulHol, Hagiographie antique et démonologie, 264, mit Anm. 44 und 45. Zum Bild des Drachen als Widersacher der Heiligen und seiner Provenienz s. BoulHol, Hagiographie antique et démonologie, bes. 262-267.

23 Es ist hier zu bemerken, dass die metaphrastische Version der Vita des Stephanos des Jüngeren im Gegensatz zur entsprechenden vormetaphrastischen Version nur einmal die Bezeichnung „Drache“ ( $\delta \rho \alpha ́ \kappa \omega v)$ für den Kaiser verwendet. Symeon Metaphrastes war anscheinend bestrebt, beleidigende Äußerungen und Bezeichnungen für den jeweiligen byzantinischen Kaiser zu vermeiden, da im Moment der Verfassung seines Menologions, nämlich im 10. Jahrhundert, die ikonoklastische Zeit bereits vorbei war und seine Texte wahrscheinlich auch vom Kaiser selbst rezipiert wurden. Ein Beispiel der metaphorischen Bezeichnung „Drache“, welche für den Kaiser bzw. dessen Soldaten in den Märtyrerakten der ersten Christen verwendet wird, bieten die vormetaphrastischen Märtyrerakten des Georg (PGeorg BHG 670a, S.3.10, S.4.3, S.4.15, S.5.33, S.6.8, S.6.27, S.10.29).

24 Der Märtyrer Georg wurde mit dem Drachen konfrontiert, diese Szene aber wird nicht in den Märtyrerakten des Georg beschrieben, sondern nur in den ihn betreffenden Wunderberichten. Die früheste Fassung des Wunderberichts über den Kampf zwischen dem heiligen Georg und dem Drachen (MiracGeorg BHG 687) ist im Codex Rom. Angelicus 46 erhalten, der ins 12./13. Jh. datiert wird, vgl. AufHAuser, Das Drachenwunder des Heiligen Georg, 31; Boulhol, Hagiographie antique et démonologie, 270, mit Anm. 84; White, The Rise of the Dragon, 152. Zur Datierung und Verbreitung der Geschichte des Drachenkampfs des hl. Georg s. Krumbacher, Der heilige Georg, bes. 296-299. Zum 
findet sich der mächtige Drache in einem offenen bzw. öffentlichen Raum und wird vom jeweiligen Märtyrer überwältigt und getötet. Diese Episoden finden also nie im geschlossenen und privaten Raum des Gefängnisses statt und werden daher hier nicht weiter ausgeführt. In den Frauenmärtyrerakten hingegen, und zwar in denjenigen von Juliana, Marina und Perpetua, treten die Drachen bzw. die Dämonen selbst ausschließlich im Gefängnisraum auf, um die Märtyrerinnen in sexuelle Versuchung zu führen.

In den Märtyrerakten der Juliana von Nikomedien ist der Umgang der christlichen Protagonistin mit der sexuellen Versuchung schon vor der Gefängnisszene sichtbar und wird dann durch die Gegenwart des Dämons im Kerker zentral. Um die Heirat mit dem paganen Senator, ihrem Verlobten Eleusios, zu vermeiden und im weiteren Sinne ihre Jungfräulichkeit unberührt zu bewahren, flüchtet sie sich in Ausreden bzw. stellt bestimmte Bedingungen: Sie werde Eleusios nur dann heiraten, wenn er das Amt des Eparchen antreten würde. Als das geschieht, teilt Juliana die zweite Bedingung mit, dass sie ihn nur ehelichen werde, wenn er zum Christentum konvertieren würde. Nach Julianas Glaubensbekenntnis wird sie von ihrem paganen Vater dem Eparchen ausgeliefert. Eleusios, welcher in Leidenschaft entbrennt, erlaubt ihr seltsamerweise, an ihrem Glauben festzuhalten, in der Hoffnung, dass sie ihn heiraten würde. Doch Juliana ist unnachgiebig und besteht auf ihrer schwer realisierbaren Bedingung (PJulNic S.150.1-21, S.151.1-26, S.152.1-24, S.153.1-7; Met-PJulNic Kap.1-5). An diesem Punkt fängt ihr Martyrium durch Interrogation und Folterung an. Im Gegensatz zur vormetaphrastischen Version wird in der metaphrastischen das Feuer der sexuellen Anziehung bzw. die feurige Liebe des Eparchen mit seiner feurigen Wut und Grausamkeit der Märtyrerin gegenüber gleichgesetzt (Met-PJulNic Kap.6 und 12). ${ }^{25}$ Laut dem Text gleicht der Eparch wegen seiner feurigen Wut und Liebe dem Feuer selbst (Tò toṽ

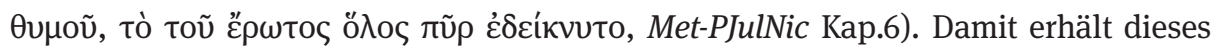
Martyrium einen stark erotischen Beigeschmack, was aber meines Erachtens noch weiter zu analysieren ist.

Die erotische Komponente des genannten Martyriums wird betont, wenn der Eparch zur Bestrafung der Unnachgiebigkeit Julianas ihren ganzen Körper mit feuri-

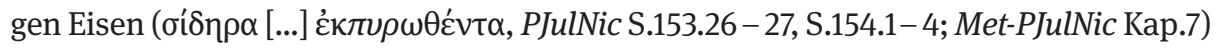

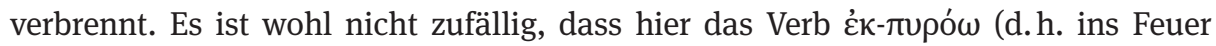
legen) verwendet wurde, dessen Stamm das Wort $\pi \tilde{v} \rho$ (d.h. Feuer) enthält. Dadurch wird die Verbindung dieser Folterung mit dem Liebesfeuer des Eparchen klar. Eines der feurigen bzw. glühenden Eisen wird geradezu zwischen die Oberschenkel Julianas gelegt, wobei bei dieser anschaulichen Beschreibung in der metaphrastischen Version

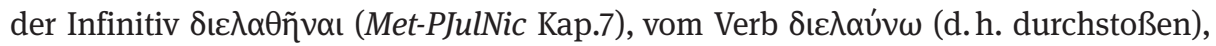

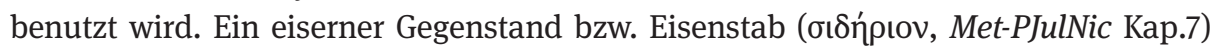

Drachenmotiv in der frühchristlichen Welt allgemein s. OGDEN, Dragons, Serpents, and Slayers und Ogden, Drakōn. Festzuhalten ist auch, dass der Drache in der metaphrastischen Version des Martyriums des Theodoros Stratelates (Met-PThStr BHG 1752) fehlt.

25 HøgEL, The Redaction of Symeon Metaphrastes, 14. 
wird also zwischen ihre beiden Oberschenkel gestoßen. Dieses Bild verweist durchaus auf den sexuellen Akt zwischen Mann und Frau, zumal sich das glühende Eisen mit dem männlichen Glied parallelisieren lässt. Eleusios, der bereits am Anfang des

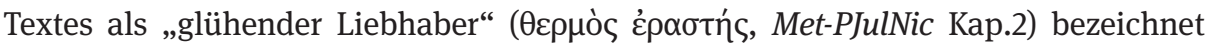
wird, kann sein sexuelles Verlangen wegen der hartnäckigen Weigerung der Protagonistin, ihn zu heiraten, nicht erfüllen. Darum findet er Befriedigung in der sexuellen Folterung der Juliana.

Nach dieser Tortur wird Juliana ins Gefängnis geworfen. Die Gefängnisszene macht einen beträchtlichen Teil sowohl in der vormetaphrastischen als auch in der metaphrastischen Fassung der genannten Märtyrerakten aus, und zwar 7 von ca. 17 Druckseiten (PJulNic S.154-160) und 104 von 384 Halbzeilen in den Spalten von Patrologia Graeca (Met-PJulNic Kap.7-11). Im Folgenden werden wir auf die vormetaphrastische Fassung fokussieren, da sie die Inhaftierung der Protagonistin sowie deren Begegnung mit dem Dämon im Kerker ausführlicher und lebendiger beschreibt:

Der Eparch wurde wütend und befahl, die Eisenfesseln zum Glühen zu bringen, um sie von ihren Achseln bis zu den Schenkeln festzuhalten. Er befahl zudem, diese stark glühenden [Eisenfesseln] um ihren Körper zu legen und ihre Arme an ihren Körperseiten festzubinden und ein anderes glühendes Eisen zwischen ihre Schenkel zu legen und, sobald sie in dieser Weise gefesselt war, in den Kerker zu werfen, und zwar in das verborgene [d.h. innere] Gefängnis. Nachdem dies geschehen war und die heilige Märtyrerin Christi, Juliana, auf dem Boden [des Gefängnisses] lag, begann sie laut zu schreien und das folgende Gebet zu sprechen: [...] „Erhöre mich, Herr, und erbarme dich und durch dein Erbarmen nimm von mir die Qualen, die mich rings umfassen, und erlöse mich zusammen mit allen, die vor dir Gefallen finden. [...] Herr, [...] rette mich aus diesen Schmerzen. [...]“. [...] Während sie noch betete, erschien ihr der, welcher alle guten Handlungen zu verhindern sucht, namens Beliar, in engelhafter Gestalt und sagte zu ihr: „Juliana, der Eparch hat für dich grausame und schlimme Folterungen vorbereitet. Höre also auf mich, [...] komm und opfere und erspare dir viele Folterungen!“ Die heilige Juliana glaubte, dass er ein Engel sei, und sagte zu ihm: „Wer bist du?“ Der Dämon sagte: „Ich bin ein Engel Gottes und da Gott dir zur Seite steht, schickte Er mich, um dir zu sagen, dass du opfern und nicht bestraft werden sollst." Das überaus sittsame Mädchen stöhnte fromm zu ihrem Herrn auf, erhob die Augen zum Himmel und sagte unter Tränen: „Herr, Gott des Himmels und der Erde, verlass mich nicht, lass mich nicht zugrunde gehen und vom Widersacher [d.h. Teufel] überwältigt werden. Aber durchbohre mein Fleisch mit der Furcht vor Dir [Ps 118 (119).120] und sei mir gnädig nach Deinem Gesetz [Ps 118 (119).29] und offenbare mir, wer der ist, der mir das Nichtnützliche rät.“ Und sofort ertönte eine Stimme im Gefängnis, die zu ihr [d.h. Juliana] sagte: „Sei zuversichtlich, Juliana! Ich bin mit dir und verherrliche dich bei mir. Halte ihn, der mit dir redet, fest und finde heraus, wer er ist.“ Und sobald diese Stimme erklang, lösten sich die auf ihr liegenden Eisenfesseln auf wie Wachs im Feuer und fielen von ihr ab. Die heilige Juliana stand vom Boden auf und kam von den Schmerzen wieder zu sich, hielt ihn fest und sagte zu ihm: „Sag mir, wer du bist und woher du kommst und wer dich hierher geschickt hat.“ Der Dämon begann zu sprechen: „Ich bin Zuphenezer, ein böser Dämon [...].“ Die heilige Juliana sagte: „Und wer hat dich hierher geschickt?“ Der Dämon sagte: „Mein Vater der Satan. [...]“ Die heilige Juliana drehte seine Arme herum, fesselte ihn nach hinten und drückte ihn auf den Boden. Dann griff sie nach einigen der um sie herum liegenden Eisenfesseln und schlug ihn heftig. Der Dämon schrie laut auf und flehte sie mit den Worten an: „Meine Herrin Juliana, die du den Aposteln ebenbürtig bist, den Märtyrern angehörst, im Engelschor mitsingst und mit den Erzengeln befreundet bist, sei mir gnädig beim Thron deines Vaters, vor dem die Cherubim zittern und die Seraphim schaudern, sei mir gnädig bei der ungeheuren Kraft 
deines Gottes, verschone mich, den Erbärmlichen, beim Leiden deines Jesus Christus. “ Die heilige Juliana sagte: „Gestehe mir, welchem der Menschen du Unrecht angetan hast!“ Und der Dämon begann zu sprechen: „Ich habe vielen Unrecht angetan. [...] Ich habe viel Böses getan und niemand hat versucht, gegen mich so etwas zu unternehmen, keiner der Apostel hat meine Hand festgehalten, du aber hast mich sogar gefesselt, keiner der Märtyrer hat mich geschlagen, keiner der Patriarchen hat die Hand gegen mich erhoben. Ich habe den Sohn Gottes in der Wüste in Versuchung geführt, indem ich ihn oben auf die Zinne des Tempels stellte [Mt 4.1 und 5], und er hat mir nicht widersprochen und du [hingegen] hast mich so stark gefoltert.“ Als der Dämon mit diesen Worten antwortete, schickte der Eparch Leute ins Gefängnis, um die heilige Juliana hinauszuführen, und wenn sie sie noch lebendig finden würden, sollten sie sie vor den Richterstuhl bringen. Als die heilige Juliana abgeführt wurde, schleifte sie den Dämon mit. Der Dämon schrie laut auf und flehte sie mit den Worten an: „Meine Herrin Juliana, stelle mich nicht weiter auf die Probe, ich kann nämlich meinem Vater nicht mehr begegnen. Du hast mich ja besiegt. Warum tust du mir noch weiter weh? Die Christen sind angeblich barmherzig; du aber hast dich mir gegenüber als unbarmherzig erwiesen. "Während der Dämon das sagte, ging die Heilige über den Platz und warf den Dämon in den Badekomplex, und zwar ins Kothaus.

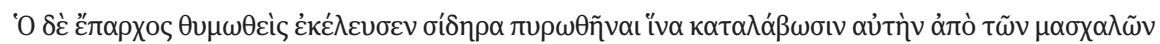

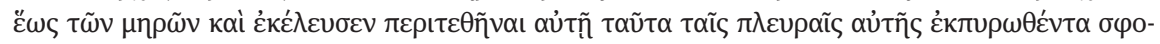

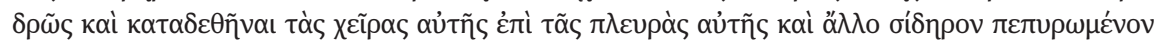

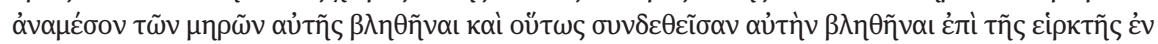

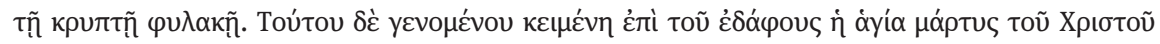

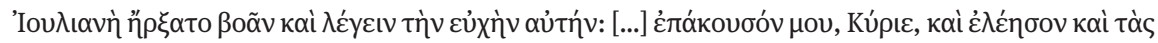

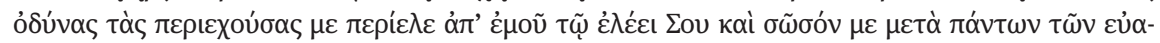

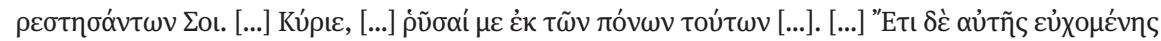

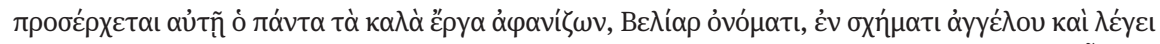

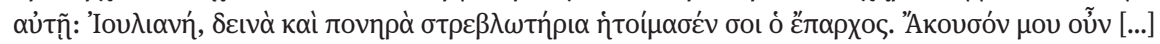

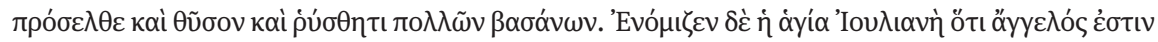

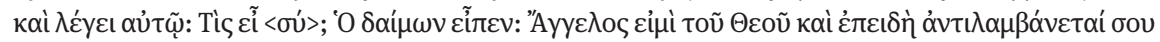

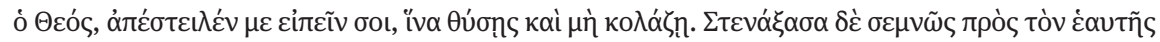

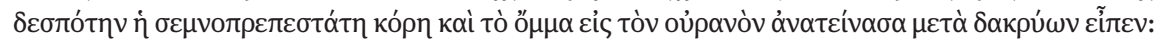

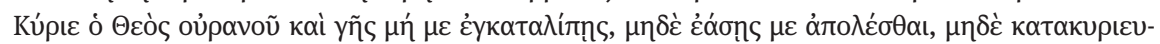

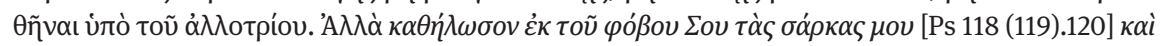

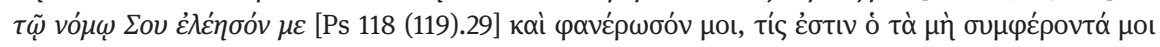

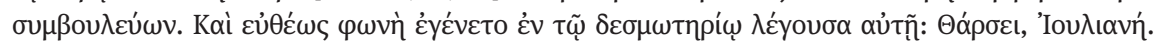

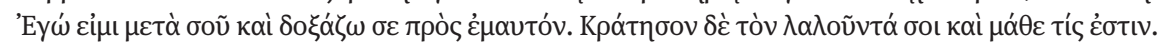

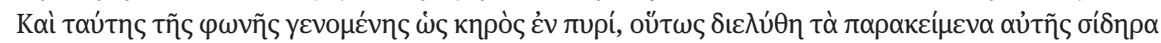

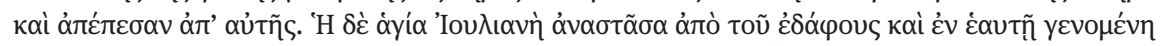

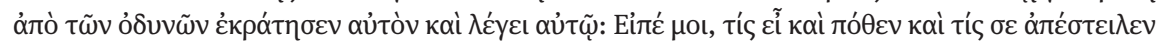

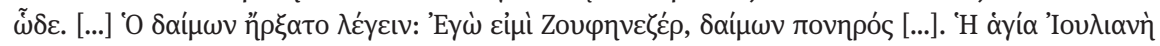

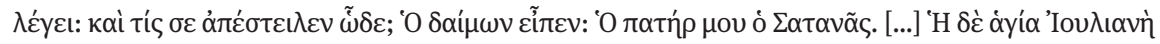

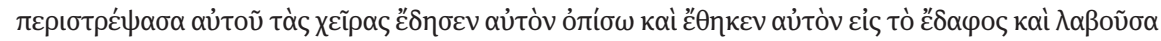

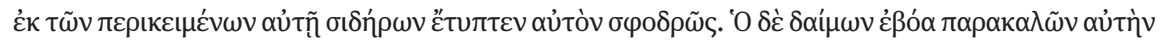

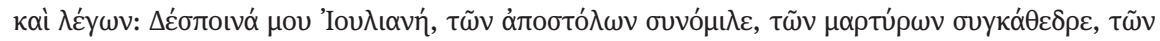

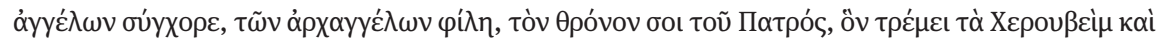

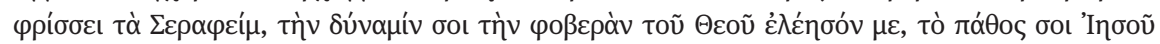

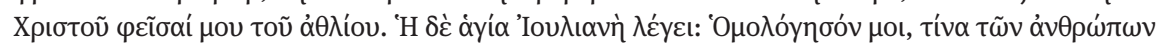

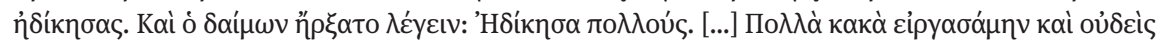

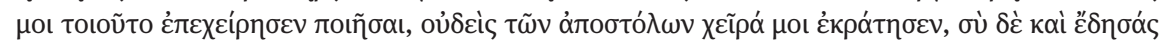

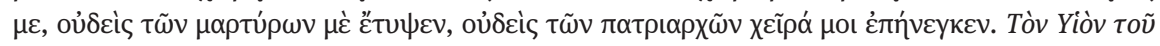

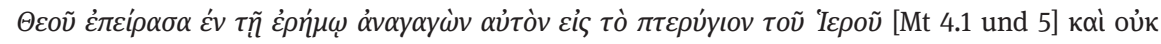




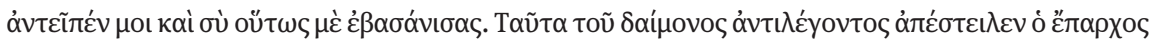

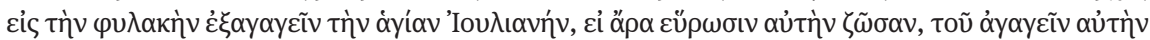

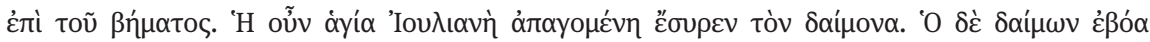

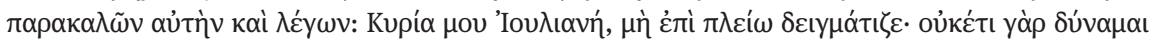

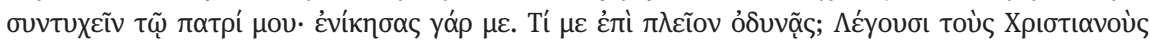

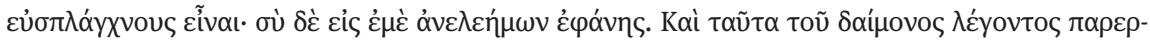

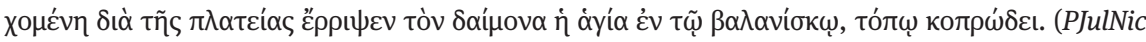
S.153.26-27, S.154.1-8, S.154.13-15, S.154.17, S.154.19-20, S.155.14-26, S.156.1-11, S.156.13-14, S.157.8-10, S.159.15-26, S.160.5-21)

Gemäß der obigen Textstelle wurde Juliana, am ganzen Körper mit glühenden Eisen malträtiert und gefesselt, vom grausamen Eparchen Eleusios ins Gefängnis gebracht, wo sie Gott darum ersucht, sie von den furchtbaren Schmerzen zu befreien. Daraufhin erscheint ein Dämon in engelhafter Gestalt, ${ }^{26}$ der die Protagonistin dazu anspornt, den Kampf aufzugeben und zum Paganismus überzutreten. Dies bringt Juliana in Verwirrung. Genau in diesem Moment erschallt die Stimme Gottes im Kerker, die die Märtyrerin ermutigt, den Dämon anzugreifen und zu verhören. Augenblicklich werden alle Folterungsmaßnahmen an der Protagonistin zunichte. Die Fesseln zerfallen und Juliana kommt zu neuen Kräften. Sie ist jetzt imstande, ein Streitgespräch mit dem Dämon zu führen, das aber schnell in einen körperlichen Ringkampf übergeht. Es ist nun der Dämon, der um Hilfe fleht. Die Märtyrerin kennt jedoch kein Erbarmen. Sie hält den Dämon fest und schlägt ihn mit den Eisen, die kurz zuvor ihr eigenes Fleisch verbrannten.

Die glühenden Eisen symbolisieren die sexuelle Versuchung, die im öffentlichen Martyrium beginnt und die Protagonistin im Gefängnis weiterhin begleitet. Der Dämon, als Vertreter von allerlei Versuchungen, erscheint im Kerker, um das böse Werk des Eparchen fortzusetzen. Oder genauer gesagt: Der Eparch wirkt als Dämon außerhalb des Gefängnisses, bis der wahre Dämon im Gefängnisraum in Erscheinung tritt. Interessanterweise ist der Eparch gemäß der metaphrastischen Version mit den

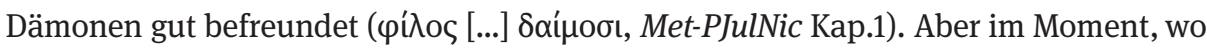
Juliana durch göttliche Intervention von den Eisenfesseln befreit wird, überwindet sie gleichzeitig alle dämonischen Anfechtungen. Juliana schlägt den Dämon mit dem glühenden Eisen und bestraft ihn auf diese Art und Weise mit seinen eigenen Mitteln. So kehrt die Versuchung zu ihrer ursprünglichen Quelle, nämlich dem Dämon selbst, als Bestrafungsform zurück.

Das Gefängnis ist zwar der Raum, in dem sich der Hauptteil des Martyriums der Juliana abspielt, aber erweist sich zugleich als eine Folterkammer für den Dämon. Hier ist ein paralleles Kräfteverhältnis zwischen dem Eparchen und Juliana sowie Juliana

26 Für das Bild des Dämons als Engel und seine Herkunft s. BoulHol, Hagiographie antique et démonologie, 262, mit Anm. 31 und 32. In engelhafter Gestalt tritt der Dämon auch während der Inhaftierung von Julitta und ihrem Sohn Quiricus (BHG 313y-313z) in Erscheinung; Quiricus führt ein Gespräch mit dem Dämon und verjagt ihn aus dem Gefängnis, vgl. KäLviäInEN, The 'epic' Greek Martyrdom of Kyrikos/Cyricus and Ioulitta/Julitta (E06118). 
und dem Dämon zu bemerken, weil sich das Verhör und die Folter sowohl der Juliana als auch des Dämons vergleichen lassen. ${ }^{27}$ Unter diesen Umständen übernimmt Juliana eine Doppelrolle. Einerseits erscheint sie als das Opfer beim öffentlichen Martyrium, nämlich den Interrogationen und Folterungen durch den Eparchen, andererseits aber tritt sie im Kerker dem Dämon in der Rolle des Peinigers gegenüber, da sie ihn zunächst völlig bewegungsunfähig macht und dann verhört und foltert. Im Wesentlichen findet hier ein paralleles Leidensgeschehen statt, zumal die Protagonistin dem Dämon verschiedene Prüfungen auferlegt, welche auch die Hauptphasen ihres eigenen Martyriums darstellen: Festnahme, Verhör und Folterung. Beim Verhör des Dämons, insbesondere durch seine Antworten auf die Fragen Julianas, werden die Mächte des Bösen und Guten bzw. des Teufels und Gottes veranschaulicht und damit bringt der Text seinem Publikum auf indirekte, aber lebendige Art und Weise eine christlich-ethische Lehre bei (PJulNic S.156.8-28, S.157.1-28, S.158.1-28, S.159.1-29, S.160.1.19). ${ }^{28}$ Interessanterweise setzt der Dämon bei seiner Folterung voraus, dass

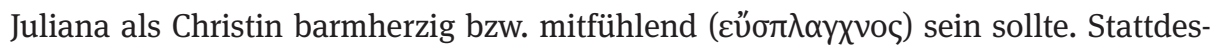
sen aber hat sie kein Mitleid mit ihm, was die unerbittliche Entschlossenheit der christlichen Protagonistin, sich selbst und ihren eigenen Glauben vor dem nichtchristlichen Widersacher zu beschützen, beweist.

Am Ende der obigen Szene ordnet der Eparch an, die Märtyrerin vor Gericht zu bringen, falls sie noch nicht im Gefängnis ihren Verletzungen erlegen sei. Dies zeigt den Grund, warum der Eparch sie einkerkerte: Er erwartete, dass das Gefängnis den Tod der schon schwer verletzten Juliana beschleunigt. Beim Verlassen des Gefängnisses schleppt sie den Dämon mit, der vor Schmerzen aufschreit und sie um Gnade

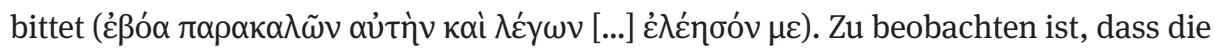
Reaktion des Dämons derjenigen der Juliana am Anfang dieser Szene sehr ähnlich ist. Auch sie schreit beim Betreten des Gefängnisses vor Schmerzen auf und bittet um

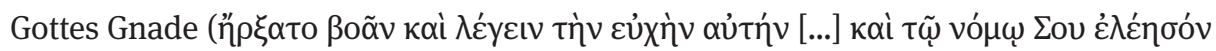
$\mu \varepsilon) .{ }^{29}$ Die Ähnlichkeit zwischen den Haltungen der beiden Figuren besteht demnach in der Äußerung ihrer furchtbaren Schmerzen infolge von Folterungen und der Bitte um Gnade. Während Juliana Gottes Gnade und Erlösung erwartet, erhofft sich der Dämon die Gnade der Schmerzerleichterung von der Protagonistin selbst. So hebt diese Episode das parallele Leiden der zwei narrativen Figuren und letztendlich den Sieg der Juliana über den Dämon hervor. Dem Dämon gelingt es also nicht, die von ihm angestrebte Rolle des Gegners erfolgreich auszuführen. Auch das Ziel des paganen Eparchen, die christliche Märtyrerin ideologisch und sexuell zu verführen, wurde bis zum Ende der Erzählung nicht erreicht und Juliana ging mit ihrer Hinrichtung als Siegerin aus dem gesamten Martyrium hervor.

27 Dazu s. auch Papavarnavas, Die Rolle des Publikums, 39.

28 Vgl. Boulhol, Hagiographie antique et démonologie, 275-276.

29 Für die Schmerzäußerung der inhaftierten Märtyrer s. ausführlich Kapitel 4. 
Als Juliana vom Kerker zum öffentlichen Martyrium bzw. zu ihrer Hinrichtung geführt wird, entfernt sie auch den Dämon vom Gefängnisraum, zu dem er gehört, da laut Tertullian - wie oben bereits erwähnt - das Gefängnis das Haus des Bösen ist. So bringt Juliana den Dämon nach draußen mit und setzt dadurch die Innenwelt mit der Außenwelt in Verbindung. Sie wirft ihn in die Latrine, nämlich an den Ort, den er verdient. Mit dieser Handlung Julianas verliert der Dämon all seine Kraft. Sein verworfener und schmutziger Charakter wird auf diese Weise mit dem Gestank und Schmutz einer Latrine verglichen. Ferner lässt sich der Bezug des Dämons zur Latrine auch auf die Bewertung der öffentlichen Badeanlagen durch die christlichen Autoren zurückführen: Christliche Autoren förderten die Zurückhaltung und Scheu vor der eigenen Nacktheit und äußerten sich daher skeptisch über die öffentlichen Badeanlagen, da sie mit der Körperpflege, der Zurschaustellung des nackten Körpers und diversen Gelegenheiten für sexuelle Kontakte verbunden waren. ${ }^{30}$ Die genannte Szene wird in der metaphrastischen Version mit dem Bild abgeschlossen, in dem Juliana

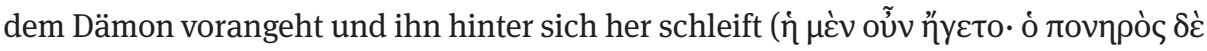

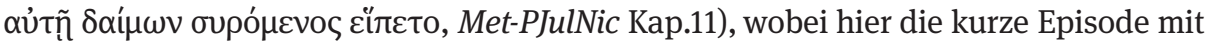
dem Dämon und der Latrine überhaupt nicht erwähnt wird.

In jedem Fall ist das Gefängnis nicht nur für die Märtyrerin, sondern auch für den Dämon ein Schwellenraum. Juliana erlangt ihre Kräfte wieder, der Dämon hingegen verliert sie und wird außer Gefecht gesetzt. Gleichzeitig kommen verschiedene Gegenaspekte, die im Grenzbereich des Gefängnisraumes koexistieren, zum Vorschein: das Böse und das Gute, die Versuchung und der Widerstand, die Gottlosigkeit und die Frömmigkeit, die Lauterkeit und die Verworfenheit, der Schmerz und die Erlösung und schließlich die Hölle durch die Gegenwart des Dämons und das Paradies durch die Anwesenheit Gottes.

Bemerkenswert ist, dass der Hagiograph durch die Worte des Dämons die Protagonistin den Engeln als ebenbürtig erachtet und sie höher als die Apostel sowie alle anderen Märtyrer und Patriarchen darstellt, da sie den Dämon mit unvergleichlichem

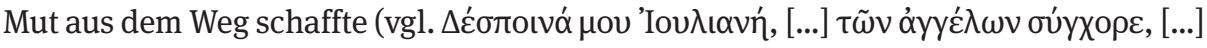

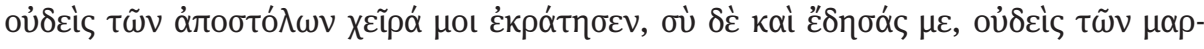

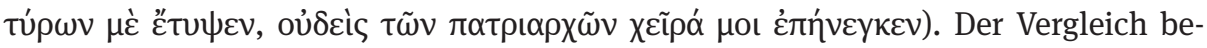
schränkt sich aber nicht nur auf hierarchische Ämter des Himmels und der Erde (Engel, Apostel, Märtyrer und Patriarchen), sondern erstreckt sich auf eine genderspezifische Ebene, indem sich Juliana als Vertreterin des weiblichen Geschlechts allen Männern - auch denjenigen mit den höchsten kirchlichen Ämtern, d.h. den Patriarchen - als überlegen erweist. Von besonderem Belang ist dabei die Tatsache, dass Juliana - im Gegensatz zu Perpetua und den cross-dressing Nonnen bzw. Märtyrerinnen (s. weiter unten) - den dämonischen bzw. männlichen Widersacher überwäl-

30 Vgl. BoulHol, Hagiographie antique et démonologie, 273. Zur ambivalenten Bedeutung des Bades in der byzantinischen Gesellschaft und Literatur s. auch BERGER, Das Bad in der byzantinischen Zeit, 132-135; YEGÜL, Baths and Bathing, 314-320; AgAPITOS, Zwischen Grauen und Wonne, 19-37; DAUTERMAN MAGUIRE - MAGUIRE, Other Icons, 121-125. 
tigt, ohne eine männliche Gestalt anzunehmen. Vielmehr zeichnet sie sich sogar durch ihre weibliche Gestalt und Natur aus. Der Hagiograph spielt auch auf die neutestamentliche Stelle des Matthäusevangeliums (Mt 4.1-11) an, in der der Teufel Christus dreimal in Versuchung führen wollte, und schreckt nicht einmal davor zurück, seine Heldin Christus selbst gegenüberzustellen. Er macht geradezu eine klare Andeutung, dass Juliana aktiver als Christus dem Dämon gegenüber war. Während Christus die heimtückische Annäherung des Teufels in der Wüste dreimal zuließ, wehrt Juliana gleich nach einer kurzen Verwirrung den Dämon ab und unterwirft ihn.

Im Allgemeinen beruft sich der Hagiograph auf die spezielle Art der Folterung seiner Protagonistin, um ihre Überlegenheit über alle anderen - zumal männlichen heiligen Figuren zu demonstrieren und sie unter den Byzantinern bekannt und beliebt zu machen. Tatsächlich stellt die eindringliche Schilderung der grausamen Behandlung der Juliana im Kerker mit den glühenden Eisenfesseln an ihrem ganzen Körper ein einzigartiges Beispiel im hier behandelten Textkorpus dar. Bei der Auseinandersetzung zwischen Juliana und dem Dämon handelt es sich also nicht nur um einen Kampf zwischen Gut und Böse, sondern auch um eine Konfrontation zwischen den beiden Geschlechtern. Diesen Kampf gewinnt eindeutig das Gute, das in den Augen des Hagiographen nur seine Protagonistin verdientermaßen vertreten kann.

Im Gegensatz zum Martyrium der Juliana, in dem der Dämon in der Form eines Engels die Märtyrerin zu täuschen versucht, erscheint er im Martyrium der Marina und in jenem der Perpetua entweder in seiner wahren Gestalt oder als gehässiger Drache bzw. als lüsterner Mann und stellt damit eine klar erkennbare Gefahr dar. Wie im Fall der Juliana nehmen die Gefängnisszenen in der hier verwendeten Edition der Märtyrerakten der Marina von Antiochien ( $B H G$ 1165) und derjenigen von Perpetua und Felicitas (BHG 1482) einen breiten Raum in der Erzählung ein: 13 von 33 Druckseiten, also mehr als ein Drittel des gesamten Martyriums von Marina (PMarAnt S.24-36) und 17 von 25 Druckseiten, d.h. über zwei Drittel des Martyriums von Perpetua und Felicitas (PPerFel Kap.3-17). Wichtig ist, dass der Kampf der Märtyrerinnen Marina und Perpetua mit den Drachen und Dämonen sowohl bei später verfassten Berichten über sie als auch in ihrem Kult Anklang findet. ${ }^{31}$ Festzuhalten ist, dass auch in den kurzen Berichten des Synaxars von Konstantinopel die Inhaftierung der Marina unter dem Datum des 17. Juli und jene der Perpetua unter dem Datum des 2. Februar erwähnt werden (SynaxCP Sp.825.14-24 [Marina]; SynaxCP Sp.440.39-51 [Perpetua]). In diesen Fällen erweist sich also die Gefängnisphase als ein integraler Bestandteil des Martyriums der beiden heiligen Frauen. Doch paradoxerweise erwähnt das Synaxar von Konstantinopel bei der kurzen Schilderung des Martyriums der Juliana von Nikomedien unter dem Datum des 21. Dezember ihre Inhaftierung und Bekämpfung des Dämons überhaupt nicht (vgl. SynaxCP Sp.333.2-20, Sp.334.2-4).

Zwischen den Märtyrerakten der Marina von Antiochien und denjenigen der Juliana von Nikomedien sind viele Gemeinsamkeiten in Inhalt und Aufbau zu erkennen.

31 White, The Rise of the Dragon, bes. 149-162. 
Das enge Verhältnis zwischen diesen zwei Märtyrerakten kann laut Pascal Boulhol zwei Gründen zugeschrieben werden: Entweder beruhen beide Texte auf denselben Quellen oder sie sind in direkter Weise voneinander abhängig. ${ }^{32}$ Wie das Martyrium der Juliana hat die Leidensgeschichte der Marina eine stark sexuelle Komponente. Genauer gesagt beginnt das Martyrium der Marina, nachdem sie die sexuellen Avancen des Eparchen Olybrios zurückgewiesen hat (PMarAnt S.17.10 - 20, S.18.21-30, S.20.27-36, S.20.1-10, S.21.11-12). Marinas Wunsch ist es, ihre Jungfräulichkeit und Seele unversehrt zu bewahren, sodass sie nach ihrem irdischen Tod bei Gott leben kann (PMarAnt S.23.19-22, S.23.32-35). Diesbezüglich sagt Marina zum Eparchen:

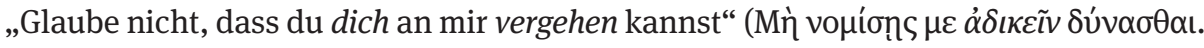

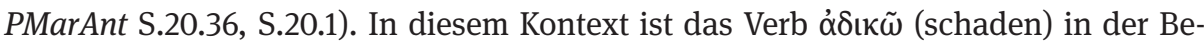
deutung „sexuell misshandeln“ zu verstehen. Festzuhalten ist, dass im Anschluss daran das genannte Verb noch zweimal in derselben Bedeutung verwendet wird.

Während ihrer Kerkerhaft wird Marina anfänglich mit einem Drachen und dann mit dem Dämon selbst konfrontiert, welche beide plötzlich aus verschiedenen Ecken des Gefängnisses hervorspringen. Nach einem schweren Erdbeben tritt im Kerker ein

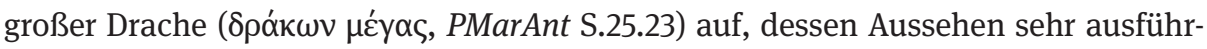
lich beschrieben wird, und zwar mit bunt gescheckter Haut, goldfarbiger Behaarung und Bart, blitzenden Zähnen, perlenförmigen Augen und silberfarbigen Augenwinkeln, blutroter Zunge und stinkendem Atem; aus seinen Nüstern stößt er Feuer und

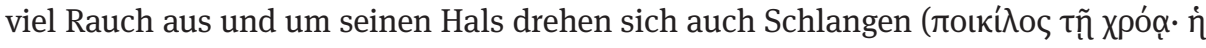

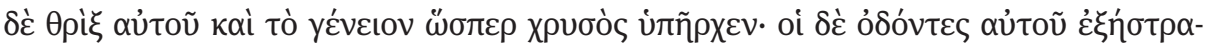

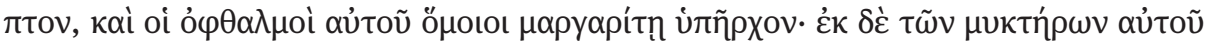

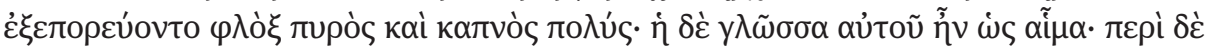

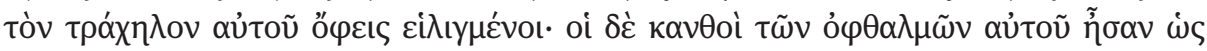
äpyupos. PMarAnt S.25.24-30). Der Drache schreit mitten im Gefängnis laut auf und bewegt sich mit einer blanken Romphaia (d.h. einem großen Schwert) schnell um die Märtyrerin, die durch seine bedrohliche Haltung ungemein eingeschüchtert wird (PMarAnt S.25.30 - 32, S.25.34).

Die von Angst beherrschte Marina richtet ein Gebet an Gott. Er möge ihr helfen, dass ihr der böse Drache, hier als Dämon bezeichnet, keinen Schaden zufügt (å $\delta$ -

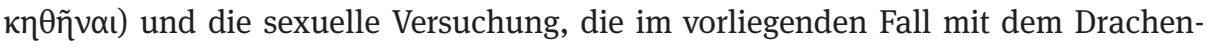
feuer $(\varphi \lambda$ ó $\alpha)$ verglichen wird, besiegt werden kann: „Unsichtbarer Gott, [...] erlaube nicht, dass ich durch den listigen Dämon [d.h. Drachen] Schaden erleide, aber dein

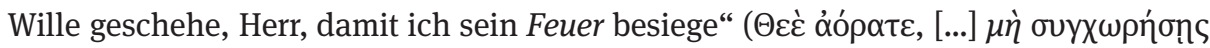

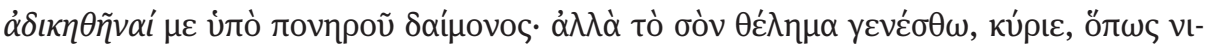

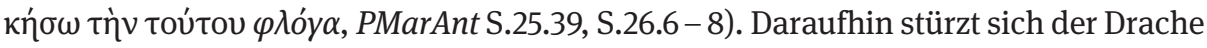
auf die Protagonistin, um sie zu verschlingen und damit ihren Körper in Besitz zu nehmen. Dies lässt sich als Vergewaltigungsversuch an Marina durch den lüsternen 
Drachen interpretieren. ${ }^{33}$ Die Protagonistin bleibt dabei unbeweglich bzw. passiv, wobei der Drache mit seiner aggressiven Haltung eine überaus aktive Rolle übernimmt. Derartige Dialektik zwischen Unterwerfung und Dominanz verweist eindeutig - auch nach der Auffassung der Byzantiner selbst - auf den sexuellen Akt zwischen einer passiven und einer aktiven Person. ${ }^{34}$ Doch als sie dann ein Kreuz schlägt, werden die Innereien des Drachen aufgelöst und sie kommt aus seinem Bauch schadlos

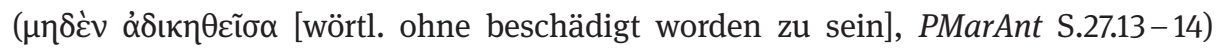

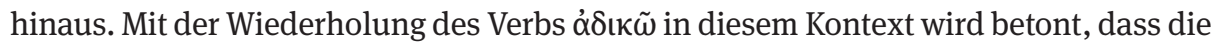
Protagonistin bis zum Ende dieser Episode nicht geschändet wurde bzw. ihre reine Keuschheit bewahren konnte.

Das Verschlingen Marinas durch den Drachen ist wohl von der im Alten und Neuen Testament geschilderten Jonasgeschichte inspiriert, gemäß der Jonas drei Tage und drei Nächte im Bauch eines Seeungeheuers verbrachte, was als Präfiguration für den Aufenthalt Christi im Grab, seinen Abstieg in die Unterwelt und letztendlich für seine Auferstehung (Jona 2.1-11; Mt 12.39-41; Lk 11.29-30) gilt. ${ }^{35}$ Im Gegensatz zur oben angeführten Szene aus den Märtyrerakten der Marina haben die biblischen Stellen keine sexuelle Konnotation, wobei sie als Zeichen für den Sieg über den Teufel und Tod sowie für die Wiedergeburt gewertet werden können. In diesem Sinne symbolisiert der triumphale Austritt Marinas aus dem Bauch des Drachen ihre spirituelle Wiedergeburt bzw. Transformation, die die Protagonistin ab jetzt bei der Bewältigung von neuerlichen sexuellen Versuchungen und Herausforderungen zu einer aktiveren Rolle veranlasst.

Gleich nach der Niederlage des Drachen durch die Märtyrerin Marina erscheint der Dämon im Gefängnis. Laut den Worten des Dämons hatte er selbst seinen Angehörigen namens Rufus in der Gestalt eines Drachen ausgesandt, um Marina zu töten (PMarAnt S.29.20 - 22). Der Dämon wird hier als dem Drachen überlegen dargestellt. Dafür spricht auch sein Name: Beelzebul (PMarAnt S.31.9) oder Satan (PMarAnt S.32.24). Bei dieser Episode handelt es sich um einen verbalen und körperlichen Schlagabtausch zwischen den beiden narrativen Figuren, der inhaltlich und strukturell mit dem entsprechenden Kampf im Martyrium der Juliana vergleichbar ist.

Die Dominanz der Marina gegenüber dem Dämon zeichnet sich bereits von Anfang an ab: Sie reißt seinen Bart und sein rechtes Auge aus, sie tritt ihm gegen den Nacken und schlägt ihm mit einem ehernen Hammer auf den Kopf. Der Dämon brüllt

33 Diese Szene sowie ihre Symbolik sind auch in der metrischen französischen Version des genannten Martyriums (12. Jh.) zu finden, in der aber die Protagonistin unter dem Namen Margareta erscheint, vgl. KaY, The Sublime Body of the Martyr, 15-16; KAY, Courtly Contradictions, 227-228.

34 Vgl. bspw. Brown, The Body and Society, bes. 9-17; Boswell, Same-Sex Unions, bes. 12, 58, 79, 154, $243-245$.

35 Für die Parallelisierung der Geschichte Marinas mit derjenigen von Jonas und Christus s. GAMILlSCHEg, Die griechischen Texte, 30; Boulhol, Hagiographie antique et démonologie, 267. Für die Jonasgeschichte und ihre Beziehung zu Christus s. Duval, Le Livre de Jonas; KAzHDAN - LOWDEN TKacz, Jonah, 1071; SHerwood, A Biblical Text and Its Afterlives, bes. 11-21. 
vor Schmerzen (PMarAnt S.29.3-13, S.30.14-19). Diese Episode muss in der byzantinischen Welt sehr beliebt gewesen sein, da sie mehrmals in der Kunst dargestellt wurde. In seiner unveröffentlichten Dissertation (1974), betitelt als Die griechischen Texte über die heilige Marina, hält Ernst Gamillscheg fest, dass die älteste Darstellung Marinas ein aus Beirut stammendes Siegel des 7. Jahrhunderts sein dürfte, auf dem die Märtyrerin einem langhaarigen Mann mit einem Hammer auf den Kopf schlägt, eine Szene, die man auch in einer der Märtyrerin geweihten Grotte im Libanon auf der unteren Schicht der Fresken antrifft. ${ }^{36}$ Interessant ist hier zu beobachten, dass die Verbreitung dieser Episode aus dem Martyrium der Marina von Antiochien bereits in der frühbyzantinischen Zeit, in der auch der Text selbst abgefasst wurde, begann und der Dämon in den visuellen Darstellungen die Gestalt eines Mannes annahm, was den genderspezifischen Charakter des Kampfes zwischen dem männlichen Widersacher und der Protagonistin noch deutlicher macht.

Das Gefängnis wird nach der obigen Episode erhellt und ein großes Kreuz zusammen mit einer Taube erscheint mitten in der Zelle. Die Taube sagt der Märtyrerin mit menschlicher Stimme, dass sie nach ihrem siegreichen Kampf mit dem Dämon

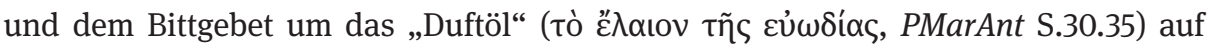
ihren Weg ins Paradies vorbereitet sei. Das „Duftöl“ sollte vor allem die Salbung bei der Taufe und im weiteren Sinne die Taufe selbst (dazu s. auch unten) symbolisieren, welche die Märtyrerin im Anschluss hieran ausdrücklich erbittet (PMarAnt S.31.6-8 [136v], S.31.1 [137r], S.38.42-56). Nach dieser „Ermutigungsdosis“ von Gott wird die Märtyrerin von ihren körperlichen Wunden geheilt und kommt wieder zu Kräften. Auf Anregung der gottgesandten Taube nimmt sie den Dämon ins Verhör und fesselt ihn bzw. macht ihn bewegungsunfähig, wobei Marina und der Dämon wie Juliana und der Dämon die Rollen des Opfers und des Peinigers wechseln. Auch der Dämon selbst bemerkt aufgrund ihrer innerlichen Erstarkung nach der Erscheinung des Kreuzes die Änderung im Aussehen und Verhalten der Märtyrerin (PMarAnt S.32.25-29). Nach ihrer Inhaftierung ist Marina imstande, ihre neue Identität als Heilige anzunehmen. Ihre Eigenart bzw. Überlegenheit als Heilige wird durch einen Vergleich mit allen

36 Ich bin Ernst Gamillscheg sehr dankbar für unser Gespräch sowie die Zurverfügungstellung des Privatexemplars seiner Dissertation mit eigenen Korrekturen und Einfügungen. Die Datierung des oben erwähnten Siegels wurde laut Gamillscheg von Werner Seibt vorgenommen. Für die Bestätigung der Datierung dieses Siegels anhand der einschlägigen Abbildung im Artikel von P. Mouterde (s. unten) bedanke ich mich bei Alexandra Wassiliou-Seibt. In Bezug auf die Schichten des oben genannten Freskos fügt Gamillscheg hinzu, dass die jüngere Schicht verschiedene Szenen aus der Vita der heiligen Maria/Marinos ( $B H G$ 1163) enthält, welche gemäß dem im libanesischen Raum verbreiteten maronitischen Kalender am 17. Juli, demselben Datum des Festtages der Märtyrerin Marina von Antiochien, gefeiert wird. Durch diese Koinzidenz der Festtage der beiden heiligen Frauen soll der Wechsel im Bildprogramm erklärt werden, vgl. GAMILLSCHEG, Die griechischen Texte, 4, mit Anm. 3. Für das Siegel und Fresko mit der hier behandelten Darstellung Marinas s. ausführlich BRossÉ, Les peintures de la grotte, 30 - 45; MouTERDE, A propos de sainte Marine, 185-186. Für weitere einschlägige Fresken im Osten und Westen aus späteren Jahrhunderten s. WHite, The Rise of the Dragon, 159-160 (mit weiteren Nachweisen). 
anderen Heiligen, welche den Versuchungen des Dämons nicht in gleichem Maße widerstehen konnten, hervorgehoben (PMarAnt S.32.16-22, S.33.39-40, S.34.21-23). Der oben diskutierte Fall der Juliana bleibt jedoch auffällig, weil sie nicht nur mit anderen heiligen Figuren, sondern auch mit Christus selbst verglichen wird.

Bei der Schilderung des Kampfes zwischen Marina und dem Dämon stehen zwei

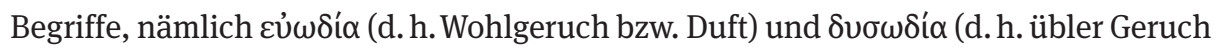
bzw. Gestank), in Opposition zueinander. Meines Erachtens können die Erwähnungen der olfaktorischen Wahrnehmungen zum Thema der Keuschheit in den Frauenmärtyrerakten wesentlich beitragen. Sowohl der Drache als auch der Dämon sind bei ihrer Beschreibung mit dem üblen Geruch verbunden; Marina hingegen will sich vor diesem Gestank schützen, wobei sie gleichzeitig nach dem Wohlgeruch strebt (PMarAnt S.25.33, S.26.12-14, S.28.31, S.28.2, S.33.9-12). An einer Stelle gibt zum Beispiel der

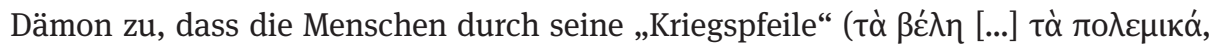

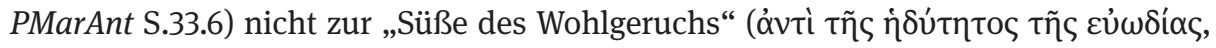

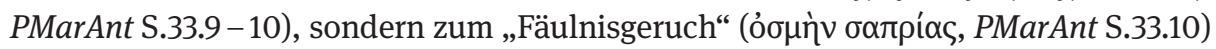
geführt werden. So werden sie durch das „brennende Feuer“ ( $\pi \tilde{\rho} \rho$ кaı́ $\mu \varepsilon v o v, P M a r A n t$ S.33.11) und die „Sünde“ ( $\alpha \mu \alpha \rho \tau i ́ \alpha$, PMarAnt S.33.12) beherrscht. Die Bilder der Kriegspfeile und des Feuers gehen auf die altgriechische Literatur, und zwar den Mythos von Eros, zurück, wobei sie leidenschaftliche Liebe und sexuelles Verlangen symbolisieren. ${ }^{37}$ Im vorliegenden Fall nehmen diese Bilder eine überaus negative Bedeutung an. Der üble Geruch kann also im Zusammenhang mit dem sexuellen Akt und dem Verlust der Jungfräulichkeit interpretiert werden, während sich der Wohlgeruch mit dem Bewahren der Jungfräulichkeit und im weiteren Sinne der Erlangung des Heiligkeitsstatus und des Paradieses parallelisieren lässt. ${ }^{38}$

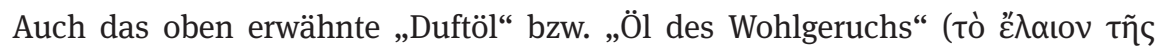

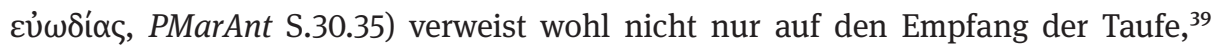
sondern auch auf die Bewahrung der Keuschheit, welche die Protagonistin selbst für ihre Verbindung mit Gott als Voraussetzung betrachtet. Es sei hier an die oben analysierten Märtyrerakten der Juliana erinnert, gemäß denen die Protagonistin den Dämon in die übelriechende und sexuell konnotierte Latrine warf, was den schmutzigen Charakter des Dämons unterstreicht. Der üble Geruch des Dämons betont also seine Absicht, die jeweilige Protagonistin sexuell zu verführen. Doch wie Juliana besiegt auch die Märtyrerin Marina den Dämon und wirft ihn wieder ins Bodenloch hinein, aus dem er ursprünglich auftauchte.

Die im Martyrium der Marina dargestellte Süße des Wohlgeruchs konnte man realiter wegen der Verwendung von Weihrauch und Duftstoffen im Gottesdienst auch in der wohlriechenden Atmosphäre der byzantinischen Kirchen wiederfinden. Auf

37 Vgl. Thornton, Eros, bes. 15-16, 28-33, 217.

38 Zum Verhältnis zwischen Geruchssinn und Heiligkeit bzw. Paradies s. auch AlBERT, Odeurs de sainteté; Evans, The Scent of a Martyr, 193-211; HARveY, Scenting Salvation; Constantinou, The Saint's Two Bodies, 285-320.

39 Für die Verbindung des Wohlgeruchs mit der Taufe s. CASEAU, The Senses in Religion, bes. 92-94. 
diese Weise bestand wohl während der öffentlichen Verlesung der genannten Märtyrerakten eine gegenseitige Ergänzung zwischen dem in der Kirche herrschenden Duft und dem entsprechenden Inhalt des Textes. Die Worte des Textes waren somit erlebbar. Durch die Geruchswahrnehmung während der Liturgie konnten die Gläubigen in die Kommunikation mit dem Göttlichen eintreten und sich das Paradies und die Heiligkeit besser vorstellen; zur Erreichung dieses paradieshaften Zustandes im Gotteshaus sollten aber gleichzeitig über die olfaktorische Wahrnehmung hinaus auch alle übrigen Sinne, nämlich die auditive, gustatorische, visuelle und taktile Wahrnehmung, beitragen. ${ }^{40}$

Im Gegensatz zu den beiden oben untersuchten Frauenmärtyrerakten, nämlich denjenigen von Juliana und Marina, in denen Drachen und Dämonen in der faktischen Realität der narrativen Figuren in Erscheinung treten, ist die Anwesenheit des dämonischen Elements in den Märtyrerakten der Perpetua nur in ihren Visionen erkennbar. Diese Märtyrerakten beginnen und enden mit der Schilderung und dem Kommentar eines anonymen Autors/Herausgebers, wobei der Hauptteil des Textes aus den persönlichen Aufzeichnungen bzw. Gefängnistagebüchern von Perpetua und ihrem Lehrer Satyros besteht. ${ }^{41}$ Laut der Ich-Erzählung im Hauptteil des Textes erscheint in der ersten Vision der im Gefängnis sitzenden Perpetua sowohl ein Drache als auch Christus (PPerFel Kap.4), wobei in ihrer vierten Vision der Teufel selbst und die Engel Gottes auftreten (PPerFel Kap.10). Während des Gefängnisaufenthalts ihres Lehrers Satyros hingegen erscheinen in seiner Vision nur Gott und die Engel Gottes (PPerFel Kap.11-13). Dies bringt uns zu meiner Ausgangsaussage zurück, dass in den Märtyrerakten die Möglichkeit der Dämonenerscheinung nur weiblichen Figuren, nämlich Märtyrerinnen, vorbehalten ist, während die Gegenwart Christi bzw. Gottes und der gottgesandten Engel sowohl bei Märtyrerinnen als auch bei Märtyrern anzutreffen ist. Die genannte Feststellung wird besonders verständlich im Lichte eines einzelnen Textes, in dem die Protagonisten, eine Frau (Perpetua) und ein Mann (Satyros), unter denselben Umständen, also in den im Gefängnis stattfindenden Visionen, unterschiedliche übernatürliche Erscheinungen (Teufel oder Gott) erleben. Dieses Genderprinzip in der literarischen Darstellung der christlichen Martyrien gilt nicht nur für die faktische Realität der Protagonisten, wie im Fall der Juliana und Marina, sondern auch für ihre Visionen, wie im Fall von Perpetua und Satyros. In der faktischen Realität

40 Zur christlichen Liturgie als einer multisensorischen Erfahrung für die Gläubigen s. CASEAU, Christian Bodies, 103, 107-109; CASEAU, Parfum et guérison, bes. 145-150; HARVEY, Scenting Salvation, bes. 99-155; CASEAU, The Senses in Religion, 89-110. Die vorteilhafte Wirkung der Duftstoffe erkannten die Byzantiner und verwendeten sie auch in ihrem Alltag, wie etwa zur Behandlung von Krankheiten oder als Krankensalbung, s. CASEAU, Parfum et guérison, 141-191. Für die Sinneswahrnehmung in Byzanz s. den jüngst erschienenen Sammelband von HARVEY - MulletT, Knowing Bodies, Passionate Souls.

41 Vgl. HABERMehl, Perpetua und der Ägypter, 1, 241-248 (mit weiteren Nachweisen); HefFernan, The Passion of Perpetua and Felicity, 3-8, bes. 5; Rebillard, Greek and Latin Narratives, 296 (mit weiteren Nachweisen). 
wie in der Visionswelt der Märtyrerinnen werden die Protagonistinnen erst während ihrer Inhaftierung mit dem Dämon konfrontiert.

In der ersten Vision, die weiter oben (Kapitel 2) angeführt wurde, verweisen die scharfen seitlichen Eisen der Leiter, die beim Erklimmen Perpetuas Fleisch zerreißen

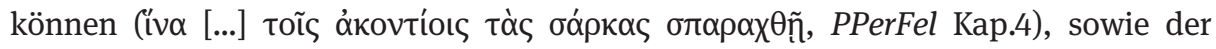

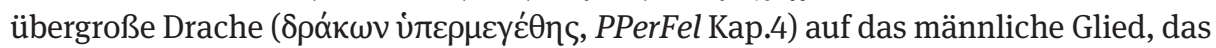
in diesem Kontext mit einer möglichen sexuellen Misshandlung assoziiert wird. ${ }^{42}$

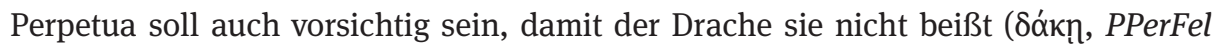

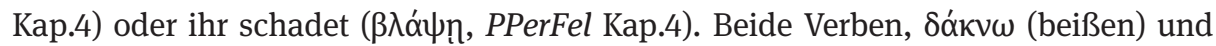
$\beta \lambda \alpha ́ \pi \tau \omega$ (schaden), betonen den sexuellen Beigeschmack hinsichtlich der Absicht des Drachen der Protagonistin gegenüber. Perpetua übersteht trotzdem mühelos die Bedrohung des Drachen, als sie seinen Kopf als erste Sprosse der Leiter benutzt und sich damit dem Paradies und dem Stand der Heiligkeit nähert.

In ihrer vierten bzw. letzten Vision ist Perpetua aufgerufen, dem Teufel selbst durch einen gefährlichen und anspruchsvollen Kampf entgegenzutreten. So lautet die besagte Passage aus dem Bericht der Perpetua:

Einen Tag vor unserem Kampf mit den Tieren hatte ich also die folgende Vision. [...] Und da sah ich eine ungeheure Volksmenge in gespanntester Aufmerksamkeit. Und ich, die ich wusste, dass ich $\mathrm{zu}$ den Tieren verurteilt worden war, wunderte mich, dass man sie nicht auf mich losgelassen hatte. Und ein Ägypter, hässlich an Gestalt, kam auf mich zu mit seinen Helfern, um gegen mich zu kämpfen. Und ein Jüngling, besonders wohlgestaltet und von strahlender Schönheit, kam zu mir, zusammen mit ihm kamen auch andere schöne Jünglinge als meine Helfer und Unterstützer. Und ich wurde entkleidet und wurde zum Mann. Und meine Beschützer fingen an, mich mit Öl einzureiben, wie man das beim Wettkampf zu tun pflegt. Und mir gegenüber sehe ich jenen Ägypter sich im Staub wälzen. Dann kam ein Mann heraus von erstaunlicher Größe, sodass er sogar den Giebel des Amphitheaters überragte, in ein Gewand gegürtet, das mit Purpur nicht nur an den beiden Schultern, sondern auch mitten auf der Brust versehen war. Er trug zudem Schuhe in verschiedenen Gold- und Silbertönen. Er hielt auch einen Stab in der Hand, wie ein Kampfrichter beziehungsweise Gladiatorenmeister. Er trug auch grüne Zweige, an denen goldene Äpfel waren. Und er gebot Stillschweigen und sagte: „Wenn der Ägypter da diese besiegt, wird er sie mit einem großen Dolch töten. Wenn sie dagegen ihn besiegt, wird sie diesen Zweig erhalten." Und er ging weg. Dann traten wir aneinander heran und begannen den Faustkampf (Pankration). Jener wollte meine Füße ergreifen, ich aber trat ihm mit den Füßen ins Gesicht. Und plötzlich erhob ich mich in die Luft und fing an, ihn so zu schlagen, als ob ich nicht mehr auf dem Boden stände. Als ich merkte, dass ich ihn überhaupt nicht verletzen konnte, schlug ich die Hände zusammen, verschränkte die Finger und fasste seinen Kopf. Dann warf ich ihn auf das Angesicht und trat ihm auf den Kopf. Und die ganze Volksmenge begann laut zu schreien und meine Unterstützer waren stolz. Und ich trat zum Kampfrichter und empfing den Zweig. Er küsste mich und sagte: „Tochter, Friede sei mit dir!“ Und sofort fing ich an, ruhmvoll zum sogenannten Tor des Lebens [d.h. Porta Sanavivaria] hinzugehen. Da erwachte ich und erkannte, dass ich nicht gegen Tiere, sondern gegen den Teufel kämpfen werde und mir wurde bewusst, dass ich ihn besiegen werde. ${ }^{43}$

42 Für das Bild der Leiter mit dem Drachen und seine sexuelle Deutung s. HEFFERnan, The Passion of Perpetua and Felicity, 174-176.

43 Die oben stehende Übersetzung basiert auf den jeweiligen deutschsprachigen Übertragungen des lateinischen Textes von Franz Joseph Dölger, Gerhard Rauschen und Peter Habermehl, die ich nach 


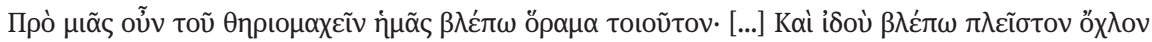

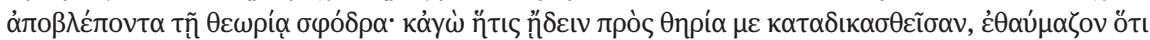

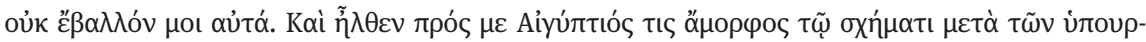

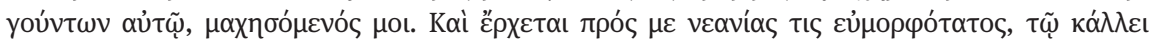

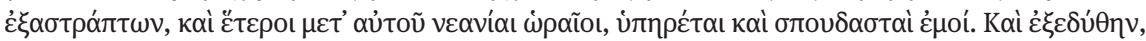

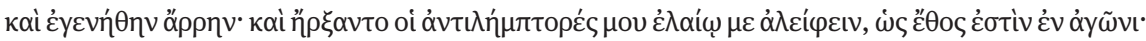

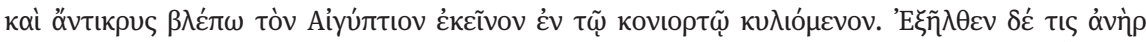

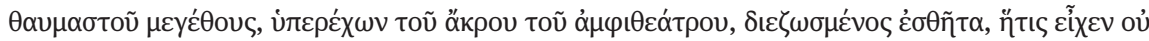

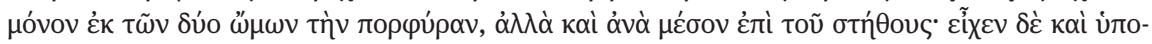

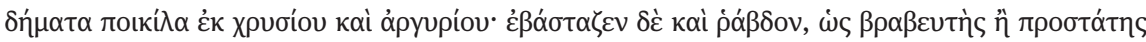

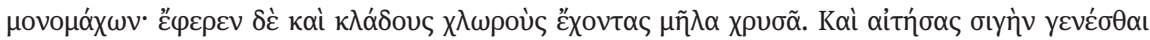

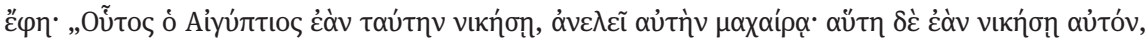

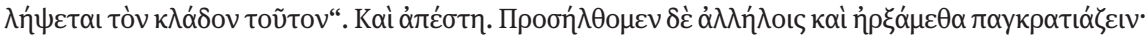

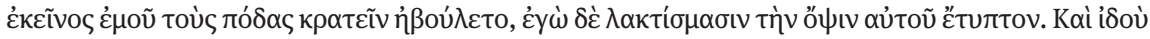

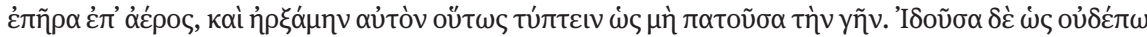

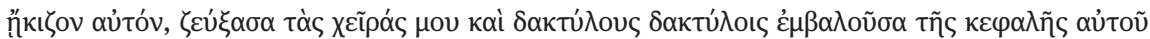

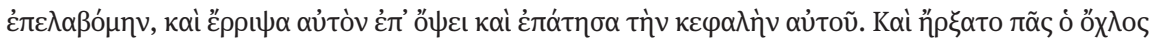

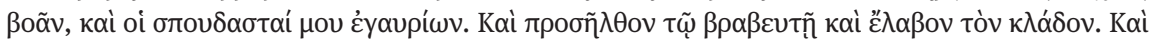

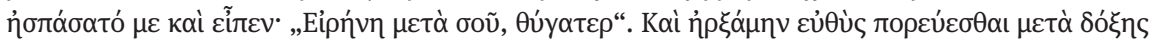

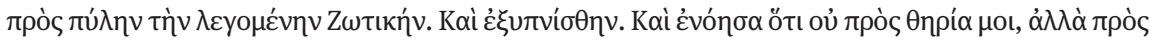

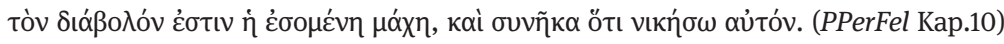

Die Verwandlung der Protagonistin in einen Mann, um gegen den dunkelhäutigen Ägypter bzw. Teufel zu kämpfen, welche im Bericht von Perpetua (zuerst in lateinischer und dann in griechischer Sprache, 3./4. Jh.) geschildert wird, stellt das einzige Beispiel in den Märtyrerakten dar bzw. kommt in späteren Texten, wie in den Märtyrerakten der Juliana von Nikomedien (5./6. Jh.) und jenen der Marina von Antiochien (spätestens im 7. Jh.), nicht vor. ${ }^{44}$ Darum verlangt der besagte Geschlechtswandel der Perpetua nach einer Deutung im Hinblick auf den hier besprochenen Hintergrund.

Die bisherige Forschung schlägt die folgenden drei Erklärungen für den Geschlechtswandel der Perpetua vor: Erstens könnte sich Perpetua - wenn auch in ihrer Visionswelt - nur als Mann Zugang zum Gladiatorenkampf verschaffen. Zweitens traten in der römischen bzw. frühchristlichen Zeit alle Gladiatoren in der Arena fast nackt an, wobei das Auftreten nackter Frauen in der Öffentlichkeit verpönt war. Durch die Verwandlung der Perpetua in einen Mann würde ihre Nacktheit beim Wettkampf mit dem Ägypter kein Problem mehr darstellen. Sonst könnte ein Kampf zwischen einem Mann und einer Frau als eine erotische Begegnung interpretiert werden, was zu vermeiden wäre. Drittens könnte Perpetua in männlicher Gestalt ihre weibliche Schwäche ablegen und somit männliche Eigenschaften, wie Mut, Klugheit und Kraft, annehmen, was für den siegreichen Kampf mit einem ernsthaften Gegner Vorausset-

Maßgabe des griechischen Textes angepasst habe, vgl. DöLger, Der Kampf mit dem Ägypter, 177-179; Rauschen, Die Akten der hl. Perpetua und Felizitas, I, 47-49 [335-337]; Habermehl, Perpetua und der Ägypter, 15, 17.

44 Vgl. auch Dinzelbacher, Der Kampf der Heiligen, 666. 
zung wäre. ${ }^{45}$ In diesem Sinne wird ihre männliche Seite besonders betont und ihre Rollen als Mutter und Tochter, die bis jetzt im Mittelpunkt des Textes standen, rücken in den Hintergrund. Diesbezüglich schreibt Peter Habermehl: „In ihrer Haft und ihrer inneren Vorbereitung auf die Hinrichtung löst sie sich mehr und mehr aus ihren alten sozialen Bindungen als Mutter und Tochter; sie legt ihre traditionelle weibliche Rolle ab und schafft sich gleichsam ein neues, männliches Ich““. ${ }^{46}$

Beim visionären Kampf der Protagonistin mit dem Teufel stellt sich eine entscheidende Frage: Wie behandeln die Märtyrerakten das Thema der Keuschheit bei Perpetua, die im Vergleich zu den beiden vorherigen jungfräulichen Märtyrerinnen bereits Mutter ist? Die Bemerkung von Thomas J. Heffernan ist zur Beantwortung dieser Frage hilfreich: „Perpetua's transformation from female to male [...] [is] part of the transformation from pagan to Christian“. ${ }^{47}$ Dementsprechend verweist ihre neue Gestalt als Mann auf ihre neue christliche Gesinnung, gemäß der man vor allem körperliche Abstinenz von allen sexuellen Genüssen und Reinheit der Seele anstreben sollte. Da sich nun Perpetua offensichtlich des christlichen Ideals der Keuschheit bewusst war, war es wohl ihr Bestreben, sexuelle Enthaltsamkeit zu üben, um die Rolle der Märtyrerin beispielhaft zu erfüllen. Ihr Übergang von einem weltlichen zu einem spirituellen Leben zeigt sich auch in der faktischen Realität durch die Haltung ihrem Kind gegenüber: Obwohl Perpetua am Anfang des Textes mit ihrem neugeborenen Kind so weit emotional verbunden war, dass sie es sogar bei sich im Kerker haben wollte, ist sie nach der Vision und dem Kampf mit dem Teufel nicht mehr um ihr Kind besorgt, was ihre spirituelle Reife bzw. Wiedergeburt signalisiert. ${ }^{48}$ In diesem Sinne lehnt sie die Mutterrolle ab und fokussiert auf die Rolle der Märtyrerin. All dies zielt meiner Ansicht nach darauf ab, die neue Identität der Protagonistin als eine moralisch wiedergeborene Frau zu betonen.

Im Zusammenhang mit den beiden anderen hier behandelten Frauenmärtyrerakten soll jetzt die Verwandlung der Perpetua in einen Mann noch weiter analysiert werden. Meines Erachtens nimmt Perpetua in ihrer Vision eine männliche Gestalt an, um die Möglichkeit einer sexuellen Vergewaltigung durch ihren Gegner auszuschließen und somit ihre Keuschheit zu bewahren. Ein gewaltsamer Verstoß gegen ihre eigenen christlichen Prinzipien in Bezug auf Keuschheit und sexuelle Enthaltsamkeit

45 Für diese drei Interpretationsversuche s. HABErmehl, Perpetua und der Ägypter, 110-119 (mit weiteren Nachweisen); Salisbury, Perpetua's Passion, 108-109 (mit weiteren Nachweisen); HeFFERNAN, The Passion of Perpetua and Felicity, 250 - 254, 262.

46 Habermehl, Perpetua und der Ägypter, 119.

47 Heffernan, The Passion of Perpetua and Felicity, 254.

48 Die Trennung bzw. Distanzierung einer Mutter von ihrem Kind war ein Zeichen für deren Spiritualität. Dies wird nochmals im selben Text bei der Leidensgeschichte der Felicitas bestätigt, welche ihre Schwangerschaft als Hindernis für ihr Martyrium auffasst und es erst nach einer Frühgeburt ihres Kindes erleidet (PPerFel Kap.15 und 18). Zum Kommentar des Martyriums der Felicitas im Zusammenhang mit ihrer Schwangerschaft s. auch HefFernan, The Passion of Perpetua and Felicity, bes. 305-310. Für ein anderes Textbeispiel, welches zwar die Trennung einer Mutter von ihren Kindern darstellt, aber die Mutterschaft verherrlicht, s. hier Kapitel 4. 
könnte wohl auch ihre Glaubensfestigkeit erschüttern, da sie sich in einer gewissen gefährlichen Situation und der daraus resultierenden Hilflosigkeit von Gott nicht genügend unterstützt fühlte. Sollte sich Perpetua nicht in einen Mann verwandeln, stünde sie der unmittelbaren Gefahr eines sexuellen Übergriffs durch den ägyptischen Mann bzw. Teufel gegenüber. Im Vergleich zu Juliana und Marina, welche beide in der faktischen Realität dem Bösen entgegentreten, kann Perpetua zur Konfrontation mit dem Teufel in ihrer Visionswelt auf eine Verwandlung zurückgreifen, weil in einer Traumvision alles möglich ist: „This is a dream, and as a dream it must follow the logic of dream narratives, a form which permits it to construct new orders of causality and temporal sequences not found in more naturalistic genres“. ${ }^{49}$ Es ist vielleicht nicht zufällig, dass die Bezeichnung des Teufels als „Ägypter“ auf einen dunkelhäutigen Mann hindeutet, ${ }^{50}$ wobei gleichzeitig die Dämonen in schwarzer Gestalt mit einer vor allem sexuellen Sünde bzw. unerlaubten sexuellen Aktivität verbunden waren. ${ }^{51}$ Mithilfe des Geschlechtswandels gelingt es der Protagonistin, ihren Entschluss zur Keuschheit zu verteidigen.

Die Verwandlung einer Frau zur Vermeidung sexuellen Missbrauchs durch eine gewalttätige männliche Gestalt geht auf den griechischen Mythos von Daphne und Apollon zurück, gemäß dem Daphne zur Erhaltung ihrer Keuschheit in einen Lorbeerbaum ( $\delta \alpha \dot{\alpha} \varphi \vee \eta)$ verwandelt wurde..$^{52}$ Dieser Mythos wurde bereits im 1 . Jahrhundert n. Chr. in Ägypten und Nordafrika christianisiert und später im ganzen Reich verbreitet. ${ }^{53}$ So diente Daphne mit ihrem Widerstand gegen die sexuelle Begierde Apollons als ein christianisiertes Symbol der Reinheit, der Keuschheit und der Jungfräulichkeit, Tugenden, die auch durch die christlichen Märtyrerinnen vertreten werden. ${ }^{54}$ Tatsächlich wurde Daphne schon in den ersten christlichen Jahrhunderten mit der ersten Märtyrerin Thekla verbunden, da auch die Letztere gemäß den im späten 2. Jahrhundert abgefassten Akten von Paulus und Thekla durch eine Veränderung ihrer Gestalt eine sexuelle Verführung vermeiden wollte; sie verkleidete sich auf ihrer Suche nach Paulus in Myra als Mann, um ihre Jungfräulichkeit im Zuge ihrer Reise

49 Heffernan, The Passion of Perpetua and Felicity, 249. Diese Meinung äußert er wiederholt in seinem Kommentar zu den Visionen der Perpetua, vgl. Heffernan, The Passion of Perpetua and Felicity, 168-169, 248-254. Für die Funktion der Visionen im Gefängnis s. hier Kapitel 2.

50 HABERMeHL, Perpetua und der Ägypter, 145-160.

51 Vgl. Guy, Les Apophtegmes des Pères, 244-245, mit Anm. 1; WortLey, Death, Judgment, Heaven, and Hell, 62, 64-65.

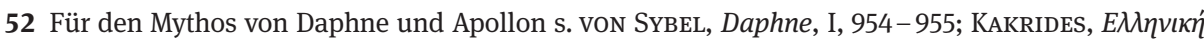
$\mu v \theta o \lambda o y i ́ \alpha$, II, 150 - 152 (mit einschlägiger Abbildung).

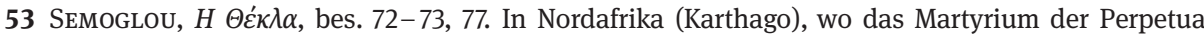
stattfand und ihre Märtyrerakten verfasst wurden, war also dieser Mythos bekannt. Für Nordafrika bzw. Karthago als historischer Hintergrund des Martyriums von Perpetua s. insb. HABERmeHL, Perpetua und der Ägypter, bes. 31-36; CoOPER, A Father, a Daughter and a Procurator, 685-702.

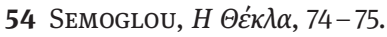


nicht zu gefährden (ActPaulThec BHG 1710-1713, Kap.40, vgl. Kap.25). ${ }^{55}$ Die Verwandlung der Märtyrerin Perpetua in einen Mann sollte meiner Meinung nach innerhalb dieser Tradition untersucht und interpretiert werden. Die ursprüngliche bzw. lateinische Version der Geschichte Perpetuas, verfasst am Anfang des 3. Jahrhunderts in Nordafrika (Karthago), folgt also einerseits den zeitgenössischen Geschichten der christianisierten Daphne und der Thekla, ${ }^{56}$ und trägt andererseits wohl zur Konstruktion des literarischen Motivs der sogenannten verkleideten bzw. cross-dressing Nonnen und Märtyrerinnen bei, welches in der Spätantike sehr populär war. ${ }^{57}$

Das cross-dressing-Motiv besteht im Grunde in der Annahme einer männlichen Gestalt durch fromme Frauen, die ihre Jungfräulichkeit vor einer auferlegten Eheschließung oder der Gefahr einer sexuellen Verführung bewahren wollen. Aus demselben Grund erfolgt die oben untersuchte Verwandlung von Daphne und Perpetua. In diesem Sinne sind zwischen dem Konzept der Verwandlung und jenem der Verkleidung keine klaren Grenzen zu ziehen. Die verkleideten frommen Frauen, welche meist in ein Männerkloster eintreten, stellen sich als Männer bzw. Eunuchen dar, aber werden letztlich immer mit ihrer weiblichen Identität (entweder vor oder nach ihrem

55 Für die Verbindung zwischen Daphne und Thekla sowie die männliche Gestalt Theklas s.

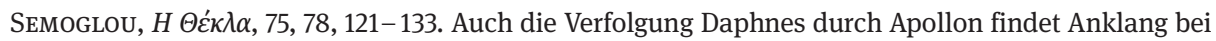
der Homilie des Pseudo-Chrysostomos zur Geschichte Theklas, gemäß der Thekla in einer Vorstadt von Ikonium namens Daphne von ihrem paganen Verlobten Thamyris verfolgt wird. Thekla will die Eheverbindung mit Thamyris vermeiden und somit ihre Jungfräulichkeit bewahren. Dazu s. SEMOGLOU, $H$

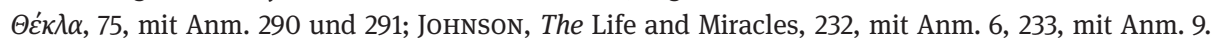
56 Für die Verbindung zwischen Perpetua und Thekla in Hinsicht auf die männliche Gestalt s. auch Heffernan, The Passion of Perpetua and Felicity, 253-254. Die Akten von Paulus und Thekla waren auch Tertullian bekannt, der zur Zeit des Martyriums Perpetuas in Karthago wohnte, vgl. PATLAGEAN, L'histoire de la femme déguisée, 608-609; CoOpER, A Father, a Daughter and a Procurator, 697. Die Verbreitung der Geschichte Theklas in Nordafrika zeigen auch archäologische Belege, vgl. SEMOGLOU, $H \Theta \varepsilon ́ \kappa \lambda \alpha, 95-96$ (mit einschlägigen Abbildungen im Anhang).

57 John Anson weist zutreffend im Jahr 1974 - wenn auch ohne Erwähnung der Daphne - auf die Möglichkeit zu einer gemeinsamen Herkunft der Verkleidung Theklas und Verwandlung Perpetuas hin: „The close analogy between the two metamorphoses [...] lends support to the theory of a common origin“, s. Anson, The Female Transvestite in Early Monasticism, 1-32, hier 10. In ihrer grundlegenden Untersuchung zum Ursprung des hagiographischen cross-dressing-Motivs im Jahr 1976 unterlässt es hingegen Evelyne Patlagean, der Verwandlung der Daphne und der Perpetua Rechnung zu tragen, vgl. PATlageAn, L'histoire de la femme déguisée, 597-623. In einer rezenten Monographie zum Thema der verkleideten heiligen Frauen schreibt Crystal Lynn Lubinsky in Bezug auf Perpetua Folgendes: „A reader who is familiar [with] Perpetua and these types of masculine descriptions may naturally read her into the stories of the female monks in order to produce an expanded textual dialogue of Christian redemption and hope, as well as masculine strength and pious womanhood“, s. LUBINSKY, Removing Masculine Layers, 100 -101, hier 101. Die verkleideten Nonnen und Märtyrerinnen wurden - ohne Berücksichtigung der mythischen Daphne und der Märtyrerin Perpetua - in mehreren literarischen Studien behandelt, dazu s. zuletzt Constantinou, Female Corporeal Performances, 90 -126; ConStantinou, Holy Actors and Actresses, 343-362; Delierneux, The Literary Portrait, 368-371. Das cross-dressing-Motiv hat auch mehrere historische Studien beschäftigt, s. z. B. HERRIN, Toleration and Repression, 181-182. 
Tod) als Heilige anerkannt und verehrt. Bereits bei der visionären Verwandlung der Perpetua sind gewisse Analogien zu erkennen: Ungeachtet dessen, dass Perpetua in der Gestalt eines Mannes gegen den Ägypter kämpft, bleibt ihr wahres Geschlecht bzw. ihre weibliche Identität unberührt. ${ }^{58}$ Auffällig ist, dass alle Erwähnungen der Perpetua im Text auf ihre weibliche Identität hindeuten. Wenn beispielsweise der Kampfrichter über Perpetua spricht bzw. sich an sie wendet, behandelt er sie eindeutig als Frau. Konkret verwendet er immer feminine Personal- und Demonstrativpronomina

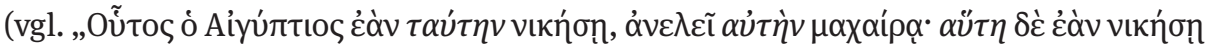

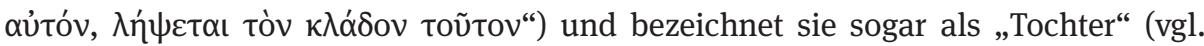
„Eịṕv

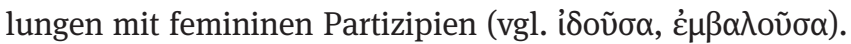

In dieser Szene geht es um eine genderspezifische Bekämpfung und Überwindung des Teufels. Falls der Ägypter die Märtyrerin überwinden würde, würde er sie mit ei-

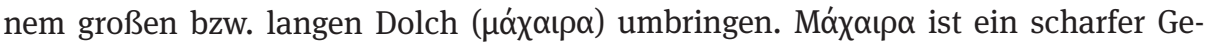
genstand, wie die oben diskutierten Eisen um die Leiter herum, und verweist in der gleichen Art auf das männliche Glied, wie auch auf die mögliche Verletzung der Keuschheit der Protagonistin. Sobald aber Perpetua dem Ägypter gegen den Kopf tritt, wie dem Drachen in der ersten Vision, ist der Kampf entschieden: Der triumphale Sieg gehört Perpetua. ${ }^{59}$ Für ihren Sieg erhält sie einen Zweig mit goldenen Äpfeln. Beim genannten Preis ist ein Paradoxon festzustellen: Im Kontext des Sündenfalls dienten die Äpfel zur Verführung Evas durch den Teufel und waren daher in der christlichen Anschauung mit der weiblichen Schwäche verknüpft. Gleichwohl werden sie im Fall Perpetuas zur Entsühnung und Aufwertung der weiblichen Natur verwendet. Dies betont abermals die starke Weiblichkeit der in einen Mann verwandelten Perpetua. ${ }^{60}$ Die Bedingungen des Zweikampfes zwischen Perpetua und dem Ägypter lassen sich dementsprechend wie folgt deuten: Der Sieg des Ägypters würde für Perpetua einen Verstoß gegen ihr christliches Prinzip der sexuellen Abstinenz, im weiteren Sinne aber auch den Abbruch des Martyriums und den Verlust ihres spirituellen Ideals bedeuten. Hingegen würde der Sieg der Perpetua die Niederlage des Bösen besiegeln. In diesem

58 Zum selben Schluss kommt auch Habermehl anhand der lateinischen Fassung des genannten Martyriums, vgl. HABermehl, Perpetua und der Ägypter, 100, 110, mit Anm. 4.

59 Das Treten gegen den Kopf des Gegners ist ein Symbol der Macht und des Sieges, dazu. s. DöLGER,

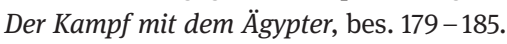

60 Joyce E. Salisbury verbindet die Äpfel weniger mit Eva und dem Sündenfall als mit der griechischen Göttin Aphrodite, die in der antiken Welt als Symbol der siegreichen Frau diente, vgl. SALISBURY, Perpetua’s Passion, 111-112. Wenn wir das hier behandelte Bild mit den Äpfeln auf weitere Beispiele der griechischen Antike zurückführen wollten, könnten wir auch den Mythos vom Urteil des Paris ansprechen, gemäß dem Paris bei einem Schönheitswettbewerb zwischen den drei Göttinnen Aphrodite, Athene und Hera die Erstere auswählt und ihr als Preis einen Apfel bietet. Der Apfel fungiert hier als ein starkes Symbol der Schönheit und Weiblichkeit. Für den genannten Mythos s. TÜrk, Paris, III,

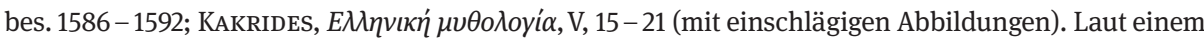
anderen Mythos konnten die goldenen Äpfel aus dem Garten der Hesperiden ewige Jugend bzw. Unsterblichkeit verleihen, vgl. von GeISAU, Hesperiden, 1117-1118. 
Sinne ist der „Zweig mit den goldenen Äpfeln“ ein Synonym für den Kranz der Unsterblichkeit bzw. den Märtyrerkranz, mit dem Perpetua gekrönt wurde.

Es ist natürlich wichtig, dass das Gefängnis als Initiationsraum zur Heiligkeit auch die oben ausgeführte visionäre Verwandlung der Perpetua beinhaltet. Durch ihre Entkleidung und Verwandlung wird die Protagonistin auf symbolhafte Weise in ihre neue Kraft und Identität als Heilige eingeweiht, wobei sie sich gleichzeitig auf die Endphase des Martyriums, nämlich ihren körperlichen Tod, vorbereitet. ${ }^{61}$ Ihre Haft spielte zweifellos eine entscheidende Rolle bei ihrer persönlichen bzw. spirituellen Entwicklung sowie der Entwicklung des tatsächlichen Martyriums und dessen schriftlicher Fassung. In ihrer letzten Vision wird sie wegen des Kampfes mit dem Ägypter in die Arena, somit in den öffentlichen Raum des Martyriums geführt, wo sie von vielen Zuschauern beobachtet werden kann. In Wirklichkeit aber befindet sie sich alleine im privaten Raum des Gefängnisses. Es handelt also von einem Gegensatz, oder besser gesagt, von einer Verflechtung zwischen dem privaten Charakter des Gefängnisses und dem öffentlichen Charakter des Zweikampfs, der aber erst durch die private Visionswelt der Protagonistin vermittelt wird.

Das Gefecht zwischen dem Dämon und der jeweiligen inhaftierten Märtyrerin scheint die biblische Tradition fortzusetzen, dass Eva als das schwache Geschlecht vom Dämon in der Gestalt einer Schlange betrogen wurde und sie dann auch Adam verleitete (Gen 3.1-24). ${ }^{62}$ Konkret gibt der Dämon Juliana gegenüber seine Schuld an der Sünde von Eva und Adam zu (PJulNic S.156.16-18). Wie schon oben betont, erscheint der Dämon ausschließlich in den Frauenmartyrien, um nochmals zu versuchen, sich das weibliche Geschlecht bzw. die Protagonistin (wie damals Eva) gefügig zu machen und dann das zu erreichen, was die paganen Verfolger beim öffentlichen Martyrium nicht erreichten, nämlich die inhaftierte Märtyrerin von ihrem Glauben abzubringen. Durch den Sieg der Märtyrerin über den Dämon wird die Stellung der Frau in der spätantiken Gesellschaft neu beurteilt. Diese Texte zielen darauf ab, dem weiblichen Geschlecht in den Augen der Byzantiner nach Evas Sündenfall eine positive Bedeutung zu verleihen. Die Märtyrerin tritt hier in die Rolle der Eva, die die böse Schlange rückwirkend besiegt. Das gute Werk der christlichen Märtyrerin geht bereits auf die Gottesmutter zurück, welche durch die Geburt Christi den Sündenfall Evas wiedergutmachte. ${ }^{63}$

61 Vgl. Habermehl, Perpetua und der Ägypter, bes. 124-129; SALISBury, Perpetua's Passion, 109.

62 Über den Fall von Eva und dem Dämon im Alten Testament hinaus gibt es im Neuen Testament das Bild einer durch den Dämon bzw. Drachen verfolgten (schwer identifizierbaren) weiblichen Figur (Offb 12.1-17).

63 Für die Rolle der Gottesmutter als „neue Eva“ s. einführend PoDSKALSKY, Virgin Mary, 2173-2174; PITARAKIs, Female Piety in Context, 153-166, bes. 153. Für die Gegenüberstellung der Stammmutter Eva und der Gottesmutter Maria s. auch TAlbot, Women, 117, 142; TAlBot, Female Sanctity, 1. Die Märtyrerinnen Perpetua und Blandina werden auch als „neue Eva“ bezeichnet, dazu s. HABERMEHL, Perpetua und der Ägypter, 81, mit Anm. 55, 86-87, 156, 167-168, mit Anm. 25, 169, mit Anm. 31. 
Die Verbindung zwischen den drei Faktoren, nämlich Märtyrerin, Schlange und Gefängnis, ist bereits in der Kirchengeschichte von Eusebius (CPG 3495) bei der Schilderung des Martyriums von Blandina anzutreffen:

Da nun keines der wilden Tiere Blandina berührte, wurde sie vom Holze abgenommen und wiederum in den Kerker geworfen, um sie für einen neuen Kampf aufzubewahren. In wiederholtem Ringen sollte sie Siegerin werden, um der listigen Schlange ein unvermeidliches Schicksal zu bereiten. Sie, die kleine, schwache, verachtete Christin, sollte, angetan mit dem großen, unbesiegbaren Kämpfer Christus, in vielen Waffengängen den Widersacher niederwerfen und im Ringen mit dem Kranze der Unsterblichkeit gekrönt werden, um so die Brüder zu ermuntern. ${ }^{64}$

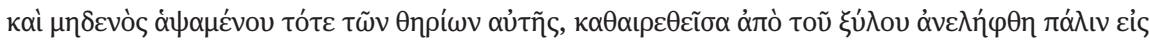

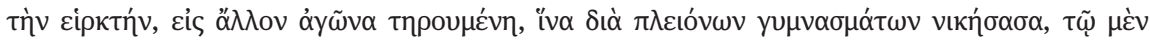

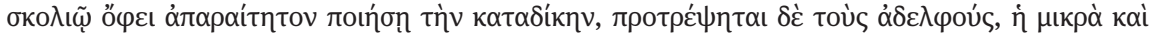

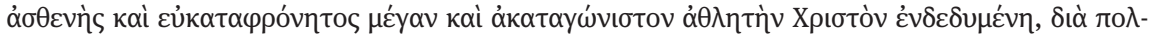

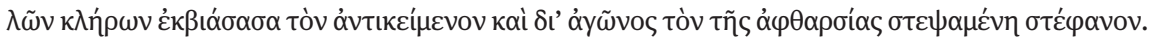
(EusHE V.1.42)

Die Märtyrerin Blandina wird im Gefängnis verwahrt, bevor sie zu weiteren Kampfhandlungen geführt wird. Im Wesentlichen gibt das Gefängnis der Märtyrerin die Möglichkeit, der höllischen Schlange mehrmals gegenüberzutreten, diese letztendlich zu bezwingen und dadurch als Vorbild zur Nachahmung für andere Christen zu fungieren. Auf diese Weise wird die Gefängnisphase nicht nur mit der Protagonistin, sondern auch mit anderen Figuren, die sie umgeben, verknüpft.

In narrativer Hinsicht dient die Gegenwart der Dämonen einem zweifachen Zweck: Zum einen legen sie den inhaftierten Märtyrerinnen Hindernisse in den Weg, um sie von der gewünschten Vollkommenheit (auf Englisch perfection) abzuhalten. Zum anderen ergibt sich durch ihren jeweiligen Angriff ein Einfluss auf Umfang und Ausgang der Erzählung, was Leser und Zuhörer auf die Folter spannt. ${ }^{65}$ Die Bemühungen der Dämonen schlagen jedoch fehl. Die Märtyrerinnen erreichen am Ende die Vollkommenheit bzw. die Heiligkeit, wobei die Erzählung durch die aufeinander folgenden erfolglosen Unternehmungen der Dämonen, die Märtyrerinnen sexuell oder ideologisch zu verführen, verlängert wird. Ein Sieg der Dämonen über die Märtyrerinnen hätte die Erwartung des Publikums enttäuschen und die Erzählung zu einem allzu schnellen Ende bringen können. Es ist also nicht zufällig, dass all diese Gefängnisszenen sehr umfangreich sind und als unabhängige Erzähleinheiten in den besagten Märtyrerakten gesehen werden können. Durch die ausführliche Beschreibung des endlosen und mühsamen Kampfs der jeweiligen Protagonistin gegen den Dämon wird das Ende der geschilderten Gefängnisszenen und damit aber auch das Ende der gesamten Erzählung verzögert. In diesen Fällen können wir von einer gen-

64 Für die deutsche Übersetzung s. HäUSER, Eusebius. Ausgewählte Schriften, 216. Vgl. dazu DöLGER, Der Kampf mit dem Ägypter, 186.

65 Vgl. dazu die Bemerkungen von Geoffrey G. Harpham zur Rolle der Dämonen in der Vita Antonii: HARPHAM, The Ascetic Imperative, bes. 77-79. 
derspezifischen Erzählmethode sprechen, da das dämonische Moment, das nur in Frauenmärtyrerakten vorkommt, die ganze Erzählung wesentlich beeinflusst. Dementsprechend bestimmt das Geschlecht der Protagonistin das Erzählen bzw. gibt der Gefängnisszene und im weiteren Sinne dem gesamten Martyrium eine Genderidentität.

Schließlich handelt es sich beim Gefecht gegen den Dämon in den Frauenmärtyrerakten um ein Ringen der Protagonistinnen mit ihrer eigenen Sexualität. Bereits in der frühchristlichen Zeit wurden Leidenschaften/Emotionen meist als von außen an den Menschen herantretende Kräfte aufgefasst, welche durch die sinnliche Welt ausgelöst werden konnten; daher werden in der Regel negativ betrachtete Emotionen, wie etwa sexuelle Begierde und Unzucht, als die Tugendhaften angreifende Dämonen dargestellt. ${ }^{66}$ Negative Emotionen und Versuchungen sollten jedoch die Märtyrerinnen nicht nur äußerlich durch die Beherrschung des Körpers, sondern auch innerlich durch die Beherrschung der (schlechten) Gedanken (logismoi) bezwingen. In seinem Buch The Making of Late Antiquity (1978) macht Peter Brown folgende Bemerkung: „The demonic stood not merely for all that was hostile to man; the demons summed up all that was anomalous and incomplete in man“. ${ }^{67}$ Unter diesem Aspekt betrachtet, lässt der jeweilige Dämon die Erzählung nicht zur Vollendung kommen, da auch die Protagonistin noch nicht vollkommen und bereit zum Märtyrertod ist. So kann der Dämon mit dem schwächeren Ich bzw. der schwachen Seite der Protagonistin identifiziert werden, die mit Zähnen und Klauen bekämpft und am Ende besiegt werden soll. Die Schilderung des Dämons als eine externe Bedrohung fungiert nämlich auch als Metapher für die Innenwelt der Protagonistin und deren Anliegen. Genau dieses innere Ringen mit ihren eigenen Gedanken und Emotionen wird durch die Erscheinung von Dämonen in der Außenwelt dargestellt, die in der Erzählung eine feste Gestalt annehmen und dadurch für Leser und Zuhörer besser veranschaulicht werden. ${ }^{68}$ Dabei entsteht eine Verflechtung zwischen Außen- und Innenwelt. Dies gilt

66 Hinterberger, Emotions in Byzantium, 128, 131. Von Emotionen ist hauptsächlich im nächsten Kapitel die Rede.

67 Brown, The Making of Late Antiquity, 90. Vgl. auch HARPHAM, The Ascetic Imperative, 79. Den ersten Versuch zur Verbindung der dämonischen Bedrohungen mit der Innenwelt des Menschen der Spätantike machte Peter Brown bereits in seinem Werk The World of Late Antiquity (1971): „To sin was no longer merely to err: it was to allow oneself to be overcome by unseen forces“: BRown, The World of Late Antiquity, 53.

68 Es sei hier erwähnt, dass der Patriarch von Konstantinopel Methodios I. während seines Aufenthalts in Rom (815-821), verfolgt vom ikonoklastischen Kaiser Leon V., mehrere Scholien zur Gefängnisszene der Marina von Antiochien in die älteste einschlägige Handschrift (Paris. gr. 1470, spätes 9. Jh.) bzw. ihre Vorlage eigenhändig eintrug, vgl. UsEnER, Acta S. Marinae, 3-14; EHRHARD, Überlieferung, I, 22; GAmillscheg, Die griechischen Texte, 5. Das vierte Scholion ist hier von Interesse: „Wie sollte man denn glauben, dass die Heilige durch die Gnade [Gottes] den Feind geistig besiegte, wenn er nicht erschienen wäre und sie ihn nicht in wahrnehmbarer und sichtbarer Weise ,entnervt ${ }^{\star}$ [d. h. bezwungen]

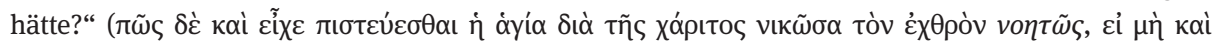

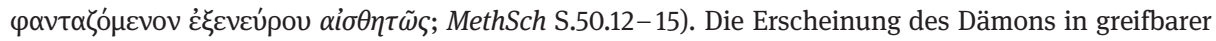


nicht nur für Juliana und Marina, die mit dem Dämon als einer greifbaren Kreatur konfrontiert sind, sondern auch für Perpetua, in deren Martyrium der Dämon als eine visionäre Figur erscheint.

Die Sexualität von Frauen wird in der byzantinischen hagiographischen Literatur insbesondere auf zwei Weisen offengelegt: Zum einen können Frauen eine ,aktive Sexualität“ vertreten, im Sinne, dass sie sich als Subjekt sexueller Tätigkeiten darstellen, um das sexuelle Interesse der Männer zu erregen. Ein bekanntes Beispiel dafür ist die heilige Maria von Ägypten, die in der ersten Phase ihres Lebens ihrer eigenen sexuellen Begierde folgt und zur Prostituierten wird (VMarAeg BHG 1042, Kap.18-23). Zum anderen werden Frauen häufig mit einer „passiven Sexualität“ geschildert, nämlich als Objekt sexueller Avancen von ungläubigen Männern, welche sie auch zu vergewaltigen versuchen (s. weiter unten). Gemäß dem christlichen Ideal sollten also Frauen alle inneren und äußeren sexuellen Versuchungen unterdrücken bzw. abwehren. ${ }^{69}$ In der christlichen Wahrnehmung waren die sexuellen Verlockungen wegen der Promiskuität der griechischen Götter mit Paganismus gekoppelt. Vor allem der Göttervater Zeus erscheint in den hagiographischen Texten als eine besonders unmoralische Figur (s. z.B. PMarCr BHG 1196, S.394.22-25; PEustAuxEugMarOr BHG 646, Kap.22). Ebenso wird der Dämon in den Märtyrerakten als eine unmoralische Gestalt skizziert, welche die verdrängte und zugleich verbotene Sexualität der Protagonistinnen versinnbildlicht. Die Märtyrerinnen wollen nämlich in ihrem Widerstand gegen Paganismus und Immoralität keinen sexuellen Versuchungen erliegen. Letztlich sollten die inhaftierten Märtyrerinnen als christliche Vorbilder für Frauen den „Dämon“ der Sexualität überwältigen.

Die verbale und körperliche Auseinandersetzung der jeweiligen Märtyrerin mit dem Dämon bzw. mit sich selbst im Gefängnis ist von größerer Bedeutung als jene mit dem paganen Gegner, da die Erstere die Identität der Protagonistin als Heilige vollständig und endgültig bestimmen kann. Beim Verlassen des Kerkers ist die Protagonistin fest entschlossen, die Endphase des Martyriums bzw. den Tod zu erdulden und deswegen kommt auch die Erzählung gleich danach zum Ende. Hierbei ist festzuhalten, dass die besagten Gefängnisszenen nicht als eine Atempause für die Protagonistin und das Publikum wie in anderen Fällen dienten, weil genau an diesen Stellen der Schwer- und Höhepunkt der gesamten Geschichte stattfindet. In diesen Szenen kulminiert die Spannung des Publikums wegen des Zweifels und Schwankens

Gestalt in der Erzählung zielt also meines Erachtens darauf ab, das Publikum vom inneren Kampf und Sieg der Protagonistin über allerlei Schwächen zu überzeugen. Die Skepsis des Scholiasten gegenüber der Realität der Gefängnisszene wird laut Ernst Gamillscheg auch in anderen Scholien (z. B. II, VIII, X und XII) angedeutet, vgl. Gamillscheg, Die griechischen Texte, 41-42, 43, mit Anm. 7, 45-46, 47, mit Anm. 2, 48, 50. Für die Edition der Scholien des Patriarchen Methodios I. s. Usener, Acta S. Marinae, 48-53. Zur Interpretation der Drachenerscheinung als innerer Kampf Marinas s. auch MERKELBACH, Drache, 247. Peter Dinzelbacher glaubt dagegen, dass für die mittelalterlichen Menschen der Teufel „ein sehr konkretes und lebendiges Wesen“ sei, dazu s. Dinzelbacher, Angst im Mittelalter, 9-10, 24.

69 Vgl. SHaw, The Virgin Charioteer, bes. 200 - 210. 
der Protagonistin sowie wegen des ungewissen Ausgangs. So wird der Dämon bzw. das schwache Ich der Protagonistin zum Teil des Schwellenraums des Gefängnisses. Der geschlossene Gefängnisraum spiegelt den Raum des Geistes der Protagonistin wider. Als zum Beispiel Juliana den Dämon besiegt, wirft sie ihn aus dem Gefängnis. Das symbolisiert die Ruhe und Glaubensfestigkeit, die sie jetzt innerlich beherrschen. Kurz vor Schluss der Erzählung erscheint der Dämon wieder, um das Urteil der Paganen zur Hinrichtung der Märtyrerin gutzuheißen. Beim flüchtigen Blick der Protagonistin auf ihn wird er aber gleich von Angst beherrscht und verschwindet ganz und gar (PJulNic S.164.23-32; Met-PJulNic Kap.14). Der Dämon stellt keine externe oder interne Bedrohung mehr dar.

\section{III.2 Die inhaftierte Märtyrerin gegen ungläubige Männer}

Die Episoden, in denen pagane Männer in den Kerker eintreten, mit dem Ziel, die inhaftierten Märtyrerinnen sexuell zu missbrauchen, können wie diejenigen mit dem dämonischen Element die christlichen Frauen bei ihrem Weg zur Heiligkeit beeinflussen. Die nichtchristlichen Verfolger wollen nämlich durch eine Vergewaltigung die Märtyrerinnen bezwingen und ihre spirituelle Entwicklung behindern. Im Gegensatz zu den Märtyrerinnen erleben die inhaftierten Märtyrer keine Vergewaltigungs- bzw. Verführungsversuche weder von anderen Männern, wie etwa Wächtern und Mitgefangenen, noch von Frauen, die sich eventuell im selben Kerker als Mitgefangene befinden oder als Besucherinnen vom paganen Statthalter geschickt werden könnten, um dem Märtyrer den Kopf zu verdrehen. Insgesamt werden solche Episoden nur in den Leidensgeschichten von Märtyrerinnen angetroffen, was die Genderidentität der betroffenen Erzählungen bestärkt.

Ein solches Beispiel findet sich im Martyrium von Domna und Indes (PDomInd BHG 822z, Kap.18; Met-PDomInd BHG 823, Kap.19-22): Eine weibliche Nebenfigur, die Christin Theophilia bzw. Theophila/Theophile, ${ }^{70}$ ist in einem Haus (õ̃रoৎ, oikíokoৎ, oikí $\alpha$ ) in Nikomedien eingesperrt und sieht sich mit den sexuellen Avancen ihrer paganen Aufseher konfrontiert. Sie wollen die christliche Frau sexuell missbrauchen, doch werden ihre Pläne durch eine göttliche Intervention durchkreuzt. Als einer der Wächter in den Haftort der christlichen Frau eindringt, um „die unerlaubte Handlung“

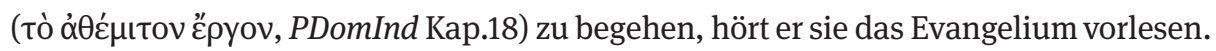
Vor Schreck wie gelähmt fällt er tot der Märtyrerin zu Füßen. Der zweite, der die christliche Frau zum selben Zweck besucht, verliert sein Augenlicht. Alle, die dieses „zügellose Verlangen“ ( erleben eine ähnliche Bestrafung bzw. konvertieren zum Christentum. Ein Engel

70 Als Theophilia ( $\left.\Theta \varepsilon \circ \varphi \iota \lambda i^{\prime} \alpha\right)$ erscheint sie in der vormetaphrastischen Version (PDomInd Kap.18) und als Theophila $\left(\Theta \varepsilon \circ \varphi i^{\prime} \lambda \alpha\right)$ bzw. Theophile $(\Theta \varepsilon о \varphi i ́ \lambda \eta)$ sowohl in der vormetaphrastischen (PDomInd Kap.27) als auch in der metaphrastischen Fassung (Met-PDomInd Kap.19, 20, 37). 
bringt letztendlich die Märtyrerin aus diesem Haus weg und führt sie zur Kirche von Nikomedien, die nach dem Text vom Kaiser Maximian in Brand gesteckt wurde. ${ }^{71}$ So starb sie den Feuertod und wird am Ende der Erzählung zu den Märtyrern und Märtyrerinnen dieser Geschichte gezählt (PDomInd Kap.27; Met-PDomInd Kap.37).

$\mathrm{Zu}$ bemerken ist, dass der Autor bereits am Anfang der oben angeführten Geschichte durch die Bezeichnungen des Haftortes auf die böswillige Absicht der Wächter hinweist. Das Haus, zu dem die paganen Verfolger die Märtyrerin zur In-

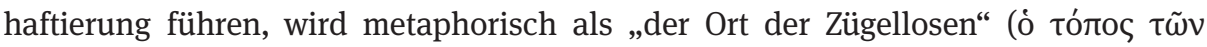

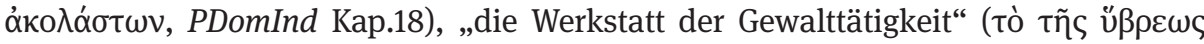

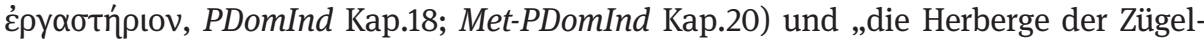

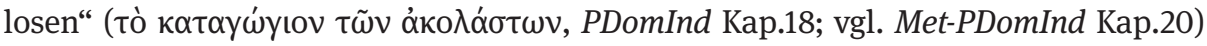
charakterisiert. In Wirklichkeit nimmt der Haftort ein Merkmal der paganen Verfolger an und wegen deren frevelhafter Handlungen der Märtyrerin gegenüber wird auch er derart negativ beschrieben.

Sowohl die paganen Soldaten bzw. Wächter als auch Kaiser Maximian selbst benehmen sich so skrupellos wie die von Dämonen besessenen Menschen. Tatsächlich betont der Autor der vormetaphrastischen Version, dass ihre Entscheidungen und Aktionen vom Teufel motiviert sind (PDomInd Kap.18). Am Ende werden die Paganen entweder von Gott bestraft oder vom Bösen befreit. Aus Bewunderung für den göttlich inspirierten Widerstand der Märtyrerin, mit dem sie ihre Vergewaltigung verhindern kann, und wegen der glänzenden Anwesenheit des schönen Jünglings bzw. Engels an ihrem Haftort treten einige Soldaten zum christlichen Glauben über. Dieser Übertritt zur christlichen Religion kann hier die Bedeutung einer metaphorischen Läuterung vom Bösen annehmen. Mit anderen Worten kann die Szene des Vergewaltigungs- bzw. Verführungsversuchs nicht nur die Identität der Märtyrerin, sondern auch jene der paganen Gegner beeinflussen oder sogar bestimmen.

Ein weiteres Beispiel bietet die Leidensgeschichte der drei jungen Schwestern Agape, Irene und Chione. Ihr Martyrium wird in der Form einer Nebenhandlung in den Märtyrerakten der Anastasia von Rom (PAnastRom BHG 82a, Kap.9-18; Met-PAnastRom BHG 82, Kap.8-19) geschildert, welche aber einen wesentlichen Teil, also ungefähr ein Viertel der gesamten Erzählung, ausmacht. Die drei Schwestern beharren beim Verhör durch den Kaiser Diokletian in Rom auf dem christlichen Glauben und werden ins Gefängnis geschickt. Dort besucht die Protagonistin Anastasia die jungen Frauen und gewährt ihnen Unterstützung durch Ermutigung, Nahrung und Kleidung. Mittlerweile muss aber Diokletian wegen dringlicher öffentlicher Angelegenheiten nach Mazedonien fahren. So beauftragt er den Eparchen Dulcitius mit dem Verhör und der Bestrafung der drei christlichen Frauen. Der Eparch, dessen „böse Natur“ (

71 Die Brandstiftung an der Kirche von Nikomedien stellte wohl für die Byzantiner eine charakteristische Szene dieses Martyriums dar, weil sie häufig in der Form einer Miniatur die genannte Geschichte in illustrierten Handschriften (s. Vat. gr. 1613, fol. 279; Athon. Lavra $\Delta 51$ [427], fol.170r; London., B. L. Add. 19352, fol. 95v) begleitet. Zu diesen Abbildungen s. DER NERSESSIAN, The Illustrations, XXV, 227-228. 


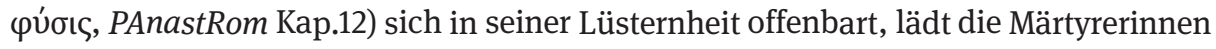
gleich vor Gericht. Während der Interrogation wird er aber zeitweilig blind und bringt aus Angst die Frauen wieder ins Gefängnis.

Im Anschluss daran werden die Aktionen des Eparchen auf folgende Art und Weise beschrieben:

Später aber, nachdem sie eingekerkert worden waren und Hymnen und Lobgesänge an Gott zu richten begannen, wollte er [d.h. der Eparch] schnell hineinstürzen und ihre vermeintliche Zauberei unversehens bloßstellen. Nach Gottes Willen aber kam er vom Weg ab und wurde irgendwie zu einem kleinen Haus in der Nähe verschlagen, das offenbar als Küche für die Aufseher diente. Da drinnen traf er auf Kochgefäße und Töpfe und hatte den Verstand verloren und glaubte, dass er die Jungfrauen in seinen Händen habe. Er erschien rußig im Gesicht, hatte ein verqualmtes Gewand und war voller Rauch und Gestank.

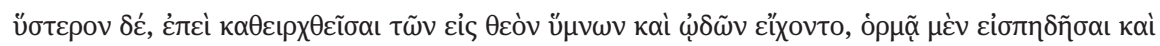

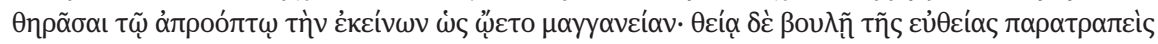

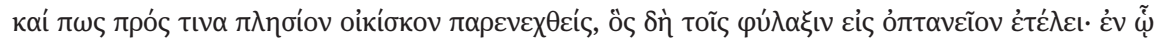

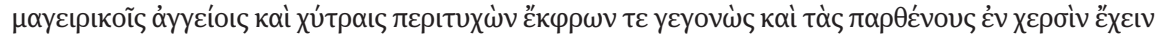

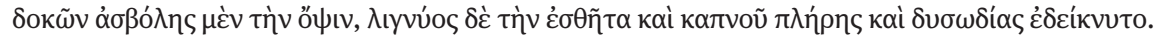
(PAnastRom Kap.12)

Die Absicht des Eparchen wird in der obigen Passage klar, obwohl sie vom Autor sehr diskret formuliert ist. Dulcitius fasste nämlich ins Auge, die Christinnen im Kerker zu besuchen und wegen ihrer Unnachgiebigkeit und angeblichen Verwendung von Beschwörungen mit einer sexuellen Bestrafung bzw. Vergewaltigung zu unterwerfen. Stattdessen aber übte er am Ende sexuelle Handlungen mit dem Kochgeschirr aus, weil er völlig verwirrt an einen falschen Ort geriet und die Küchenobjekte mit den inhaftierten Frauen verwechselte.

Zur Auslegung der obigen Textstelle sind zwei wesentliche Punkte festzuhalten: Erstens nimmt der Eparch den Auftrag des Kaisers Diokletian zur Bestrafung der Märtyrerinnen als Erlaubnis zu einem sexuellen Übergriff wahr. Das war eine beliebte Strategie, mit der die nichtchristlichen Gegner die inhaftierten Frauen dazu zwingen wollten, den Vorsatz der Keuschheit zu brechen und dem Christentum abzuschwören. So wirkt Machtmissbrauch demoralisierend und zerstörerisch. Deswegen erlaubt Gott laut den Märtyrerakten die Ausführung dieser Pläne nicht. Zweitens erinnert uns die Beschreibung des Eparchen im Moment seines sexuellen Aktes mit dem Kochgeschirr an das Aussehen der Dämonen und Drachen, welche auch dieselbe Absicht den gefangenen Märtyrerinnen gegenüber verfolgten. Von spezieller Bedeutung ist die Tatsache, dass das Wort $\delta v \sigma \omega \delta i ́ \alpha$, nämlich übler Geruch bzw. Gestank (s. hier weiter oben), in diesem Kontext in Anspruch genommen wird, um die Unangemessenheit der Absicht und der Handlung des Eparchen zu betonen.

Die oben angeführte Szene entbehrt nicht einer gewissen Komik und könnte deswegen das jeweilige (damalige und heutige) Publikum des Textes auch zum Lachen bringen, was den Unterhaltungscharakter der Hagiographie als Trivialliteratur unterstreicht. Zum Begriff „Trivialliteratur“ würde auch jede amüsante bzw. belusti- 
gende Darstellung einer Szene gehören. Unanständige Worte und sexuelle Handlungen konnten bei den Byzantinern Gelächter auslösen. ${ }^{72}$ Nach der Episode in der Küche strebt der Eparch auf den Kaiserpalast zu und sucht beim Kaiser lautstark und unhöflich um eine Audienz an. Auch die Nebenfiguren dieser Geschichte, und zwar die Stadtbewohner und die Soldaten vor dem Kaiserpalast, lachen verächtlich über ihn und halten ihn wegen seines anstößigen Benehmens für einen Narren. Mit all seinem Handeln ruft er zudem bei seiner Familie Scham hervor (PAnastRom Kap.13). Als der Eparch aber wieder zu sich kommt, schnaubt er vor Wut und befiehlt, die Märtyrerinnen nackt vor Gericht zu bringen, um sie für ihren Widerstand zu bestrafen. Ihre Kleidung vereinigt sich jedoch wie durch ein Wunder mit ihrem Körper und wird zu

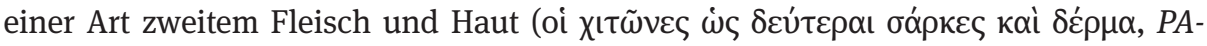
nastRom Kap.14), sodass den Zuschauern kein Anblick ihrer Nacktheit gewährt wird. ${ }^{73}$ Der Eparch wird diesmal mit völliger Blindheit bestraft.

In der Folge übernimmt der comes Sisinnius die Angelegenheit der drei Schwestern. Sisinnius verurteilt die zwei älteren Schwestern, also Agape und Chione, zum Feuer und beabsichtigt, die jüngere Schwester Irene zur allgemeinen sexuellen Verfügbarkeit in ein staatliches Bordell zu schicken. Er will nämlich Irenes Ungehorsam

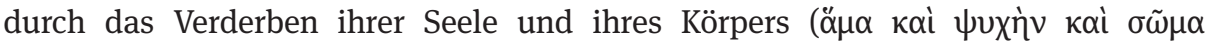
$\delta \iota \alpha \varphi \theta \alpha \rho \varepsilon \tilde{\sigma} \alpha$, PAnastRom Kap.16) ahnden. Die Protagonistin reagiert vor dem paganen Gegner mit einer sehr speziellen christlich-moralischen Interpretation der Prostitution. Nach ihrer Angabe ist eine Handlung, die mit Gewalt ausgeführt wird, obszön, und

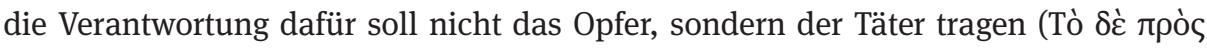

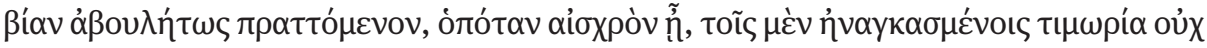

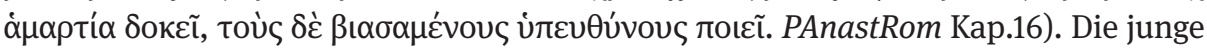
Frau stellt also klar, dass ihre mögliche Vergewaltigung „nicht ihre eigene Sünde“

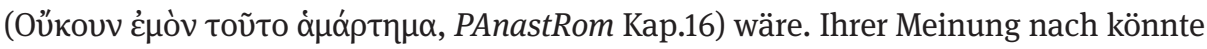
somit der Vollzug dieser Strafe ihren Weg zum Paradies nicht beeinflussen. Der Plan des comes wird realisiert und Irene kommt ins Bordell. Aber weil Gott die Jungfräulichkeit als wichtiges Prinzip für die Heiligkeit einer Märtyrerin erachtet, erspart er der Protagonistin die Vergewaltigung. Eine Armee von Engeln Gottes bringt Irene rechtzeitig aus dem Bordell und führt sie auf einen hohen Berg, wo sie am Ende vom Pfeil eines paganen Soldaten tödlich getroffen wird (PAnastRom Kap.18). Auf diese Weise

72 Vgl. Hinterberger, „Messages of the Soul“, 136-140, bes. 137.

73 Obwohl in diesem Fall die Strafe nicht erfolgreich vollzogen wurde, ist die Entblößung von Märtyrerinnen in deren Leidensgeschichten häufig zu finden (s. z. B. ActPaulThec BHG 1710 - 1713, Kap.22; PPisElAg BHG 1637z, Kap.7, Kap.10; Met-PPisElAg BHG 1638, Kap.7, Kap.10; PMarAnt S.37.19-21; VStephIun BHG 1666, S.135.22-28, S.136.1-16; Met-VStephIun BHG 1667, S.121.1318-1344, S.122.1345-1352 [Entblößung und Folterung der Anna, der Schülerin des heiligen Stephanos des Jüngeren]). Dabei stellt die Entblößung einer Märtyrerin eine Folge ihres Widerstands gegen die nichtchristlichen Verfolger dar. Zur Schilderung des nackten Körpers der Märtyrerinnen in den Märtyrerakten s. auch ConSTANTINou, Female Corporeal Performances, 34-38. 
erhält sie wie ihre älteren Schwestern den Zustand der Keuschheit bis zu ihrem Tod aufrecht.

Aus der letzten Leidensgeschichte wird ersichtlich, dass die Bestrafungen der drei Schwestern durch die beiden Vertreter des Kaisers stark sexuell ausgerichtet sind. Die männlichen Gegner versuchen nämlich hier, sowohl im privaten Raum des Gefängnisses als auch im öffentlichen Martyrium den Körper der Märtyrerinnen als Objekt ihres sexuellen Begehrens bzw. Voyeurismus zu behandeln, was Gott aber verhindert. Ihr Widerstand gegen die ungläubigen Männer wird wie beim Kampf der oben erwähnten Märtyrerinnen gegen Dämonen und Drachen mit der Erlangung der Heiligkeit belohnt. Das weibliche Element ist jedenfalls nicht nur in der Identität der Protagonistinnen, sondern auch in der mit ihnen verbundenen Erzählung vorherrschend.

Zusammenfassend konzentriert sich dieses Kapitel auf die erotische bzw. sexuelle Komponente der Gefängnisszenen, in denen Dämonen, Drachen und pagane Männer als sexuelle Bedrohung für die inhaftierten Märtyrerinnen in Erscheinung treten. Die Auseinandersetzung zwischen den Märtyrerinnen und dem dämonischen bzw. männlichen Gegner lässt sich mit dem sexuellen Spiel von Dominanz/Macht und Unterwerfung/Ohnmacht zwischen einer aktiven und einer passiven Rolle parallelisieren. Obwohl der jeweilige Aggressor bei diesem Kampf eine aktive Rolle zu übernehmen versucht, um die Märtyrerin zu verführen, werden seine Pläne durchkreuzt. Die Protagonistinnen zeigen nämlich dabei nicht die vom Widersacher erwartete Passivität, sondern widerstehen mit göttlichem Beistand allen einschlägigen Verlockungen. Während die inhaftierten Märtyrerinnen den bösen Widersacher (Dämon und Drachen) sowohl in der faktischen Realität als auch in der Vision erst nach einem heftigen leiblichen Kampf außer Gefecht setzen, werden die lüsternen Männer durch göttliches Einschreiten abgewehrt, bevor sie mit den Protagonistinnen in körperlichen Kontakt treten können. Dies spricht dafür, dass der Kampf der Märtyrerinnen gegen das Dämonische als Projektion ihres inneren und intensiven Ringens mit ihrem schwächeren Ich dient. Ihr Geist ist bestrebt, sich gegen die Leidenschaften des Fleisches durchzusetzen, was am Ende auch erreicht wird. In diesem Kontext erweist sich die Gefängnisphase für die hier behandelten Märtyrerinnen als Voraussetzung für ihre spirituelle Vollkommenheit sowie für die Erlangung ihrer Heiligkeit. Die im Gefängnisraum stattfindende Dialektik zwischen sexueller Versuchung und Widerstand stellt eine Besonderheit der Frauenmärtyrerakten dar, wobei sie einen wesentlichen Teil der Erzählung einnimmt. Im Zusammenhang mit dem Gefängnisraum wird also eine genderspezifische Erzählmethode erkennbar. 